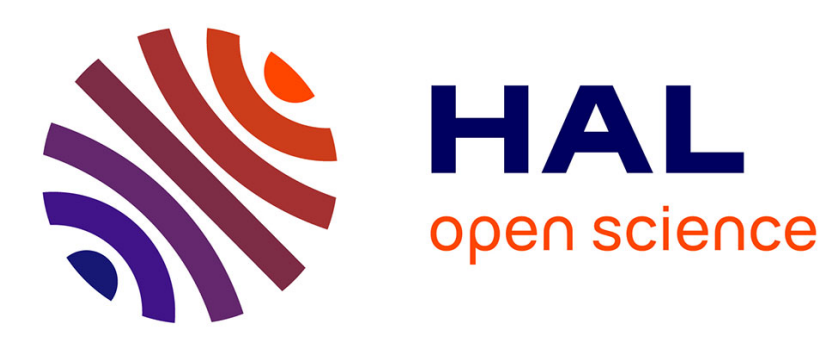

\title{
Feasible path toward $40-100 \%$ renewable energy shares for power supply in France by 2050: A prospective analysis
}

\author{
Vincent Krakowski, Edi Assoumou, Vincent Mazauric, Nadia Maïzi
}

\section{- To cite this version:}

Vincent Krakowski, Edi Assoumou, Vincent Mazauric, Nadia Maïzi. Feasible path toward 40-100\% renewable energy shares for power supply in France by 2050: A prospective analysis. Applied Energy, 2016, 171, pp.501-522. 10.1016/j.apenergy.2016.03.094 . hal-01293627

\section{HAL Id: hal-01293627}

https://hal-mines-paristech.archives-ouvertes.fr/hal-01293627

Submitted on 25 Mar 2016

HAL is a multi-disciplinary open access archive for the deposit and dissemination of scientific research documents, whether they are published or not. The documents may come from teaching and research institutions in France or abroad, or from public or private research centers.
L'archive ouverte pluridisciplinaire HAL, est destinée au dépôt et à la diffusion de documents scientifiques de niveau recherche, publiés ou non, émanant des établissements d'enseignement et de recherche français ou étrangers, des laboratoires publics ou privés. 


\title{
Feasible path toward $40 \%$ - $100 \%$ renewable energy shares for power supply in France by 2050: A prospective analysis.
}

\author{
Vincent KRAKOWSKI ${ }^{12}$, Edi ASSOUMOU2, Vincent MAZAURIC ${ }^{3}$, Nadia MAIZI2
}

\section{HIGHLIGHTS}

- Combination of thermodynamic framework and energy-planning model.

- Short-term dynamic of power systems in long-term prospective studies.

- Approach applied to renewable penetration in the French power system.

- Major role played by dispatchable power plants, imports and demand-response.

- Renewable energy penetration may jeopardize power system reliability.

\begin{abstract}
This paper explores the conditions under which renewable energy sources (RES) penetration could jeopardize power system reliability, as well as which flexibility options could help integrate high levels of RES. For this purpose, we used an energy-planning model from the TIMES family, which provides a realistic representation of power systems and plausible options for their long-term development, completed by a thermodynamic description of power systems to assess their reliability. We applied this model to the case of France and built contrasted scenarios, from $0 \%$ to $100 \%$ renewable energy penetration by 2050 . We also tested different assumptions on Variable Renewable Energy (VRE) production, imports, demand flexibility and biomass potential. We show that high renewable energy penetration would need significant investments in new capacities, new flexibility options along with imports and demand-response, and that it is likely to deteriorate power system reliability if no technologies dedicated to this issue are installed.
\end{abstract}

KEY WORDS: Prospective; Power systems; Renewable energy integration; Reliability

\section{INTRODUCTION}

\subsection{Context of the study}

Renewable energy sources (RES) have been developing rapidly since the early 2000s. Today, countries all over the world have set penetration targets for these energy sources in order to combat climate change, anticipate fossil resource depletion and solve energy dependency issues. For instance, the European Union set an objective of $20 \%$ renewable energy in final energy consumption by 2020 [1], recently extended to $27 \%$ by 2030 [2]. Many states in the United States (US) have implemented Renewable Portfolio Standards (RPS) that require suppliers to provide a minimum load using eligible RES [3]. In France, RES must account for $23 \%$ of final energy consumption in 2020 and $32 \%$ in 2030. The targets are respectively $27 \%$ and $40 \%$ in the power sector [4]. In the longer term, typically 2050, several countries or regions have designed roadmaps to achieve greenhouse gas (GHG) emissions reductions of up to $80 \%$ compared to 1990 levels. According to these roadmaps, the power sector could play a

\footnotetext{
${ }^{1}$ Corresponding author. Email : vincent.krakowski@ mines-paristech.fr

${ }^{2}$ MINES ParisTech, PSL Research University, CMA - Center for Applied Mathematics

${ }^{3}$ Schneider Electric
} 
major role in two ways: first, the GHG emissions reduction target could be higher than for other sectors (between 90\% and 100\%) and secondly, a high share of energy demand from other sectors, such as transportation, could be provided by electricity in the future [5].

Since RES are GHG-emission-free (with the exception of biomass combustion), they could represent a significant share of power production in 2050. However, some RES rely on external weather conditions: these are called Variable Renewable Energies (VREs). They do not offer the same service as conventional generators and, as consequence, high VRE penetration levels, if not carefully anticipated, could hinder power system management and strongly push up power supply costs [6]. This is the main issue addressed in this paper.

\subsection{State-of-the-art on the impacts of VRE penetration on power systems}

In order to perform relevant analyses of the evolution of power systems integrating VREs, we need to consider their specific features and the options that could help improve their integration. The potential impacts of VREs on power systems can be classified according to the temporal scale with which they are linked. Deane et al. [7] gave an exhaustive presentation of the different time scales relevant for power system security concerns and showed how VREs could weaken power system security on each of these time scales. They claimed that these scales should be analyzed together when evaluating the impacts of VRE penetration on power systems, and they proposed a methodology for coupling a Long-Term Planning Model (LTPM) with an Optimal Dispatch Model (ODM) to address this issue. LTPMs determine the cost-optimal pathway to reach certain objectives in the medium or long term. They minimize the overall cost throughout the studied period, taking into account both investments and dispatch, generally performed in a stylized way: power plants are aggregated into a single process for one technology, and hours, days and months are aggregated into a more or less small number of time slices (TS) in order to limit the computational time of the model as well as the number of assumptions to be made. In contrast, ODMs generally perform a more accurate dispatch, but only for one year and for exogenous assumptions on installed capacities. ODMs are based on an hourly representation of the supply-demand balance (or infra-hourly) taking into account technical constraints such as ramping constraints, minimal power output, and startup costs. They solve what is known as the Unit Commitment Problem (UCP). Despite the use of these two models, the authors explained that the very short time scale, which covers the ability of power systems to cope with sudden disturbances (typically the loss of an element or very quick variations of demand and production at a second or minute scale), named power system stability, was not addressed in their study and would require a third tool as well as many data. One goal of the present study, and the model we have developed, is to give insights into power system stability in LTPM without explicitly representing the very short-term dynamics involved in this issue.

Generally speaking, there are currently three ways of tackling VRE integration concerns in LTPMs:

1. Improving the representation of VRE variability directly in LTPMs with an appropriate choice of the temporal description;

2. Coupling an LTPM with an ODM;

3. Incorporating some of the short-term dynamic features of power systems directly into an LTPM in the form of additional constraints that aim at simulating some of the power system's technical requirements.

Note that another relevant issue regarding VRE integration in power systems is beyond the scope of this study, i.e. because VREs rely on dispersed resources, their penetration would certainly require a deep transformation of the grid's topology structure. Several studies have 
dealt with this issue, which remains an active field of research (for example Shawhan et al. for the Eastern part of the US [8], Hagspiel et al. for Europe [9], Pesch et al. for Germany [10], Zhang et al. for China [11]).

In what follows we focus only on LTPM-based studies since they perform an investment analysis over the whole period studied. Other studies, relying on ODM only or other tools, are well suited for answering some issues concerning the impacts of high shares of VREs, for instance the amount of storage and balancing required to prevent VRE curtailment [12], but they miss the assessment of long-term investment decisions. Therefore, they are not relevant for our investigation.

In order to deal with the first approach presented above, based on LTPMs only, Park et al. explored the optimal power mix in South Korea relying on different proportions of renewables using a TIMES model with a detailed assessment of renewables supply curves. Their study indicates a high share of solar photovoltaic (PV), from $25 \%$ to $40 \%$, in 2050 depending on the overall penetration of renewables in power production and the comparative evolution of supply costs. However, the authors do not clearly state how they dealt with intermittency issues [13]. Kannan et al. tested the benefits of increasing the temporal details of a TIMES model (STEM-E which describes the Swiss power sector) comparing an 8 time-slice (TS) model and the same model with 288 TSs. They showed that the model with fewer TSs tended to overestimate baseload capacities compared to the model with more TSs [14]. Nelson et al. conducted an analysis of low carbon scenarios for the Western North American power system (WECC) until 2030 using the SWITCH model. This model features a high level of spatial details with 50 interconnected load areas as well as a fairly accurate temporal description with 144 TSs and post-optimization hourly dispatch verification. Depending on the assumptions, a 54\% carbon emissions reduction target in 2030 compared to 1990 levels would lead to between $17 \%$ and $29 \%$ of power supply from VREs. In all of the simulated periods and for all scenarios, the dispatch verification did not find a single hour during which production could not meet demand, showing that their LTPM is quite robust for power system sizing purposes, at least for intermediate penetration levels of VREs [15]. Blanford et al. conducted a deep analysis of Clean Energy Standards in the US using the REGEN ${ }^{4}$ model and dividing the US into 15 regions. They used an algorithm to choose the 84 TSs of their model in a way that maximizes the capture of residual $\operatorname{load}^{5}$ variability. One of their results is the high need for backup capacity in the scenarios with the highest penetration of renewables, which can be reduced if grid extensions are available [16]. Ludig et al. assessed under what conditions of technology availability (carbon capture and storage and offshore wind) and demand evolution the German power system could reach the government's targets by $2050^{6}$. For this purpose they used the LIME-D model, which represents the German power system divided into 5 regions, based on 48 TSs. The TSs were built to depict the seasonal and intraday variability of demand but also different typical days of wind power production (one day with a low wind resource, one with medium wind resource and one with high wind resource). Thanks to this TS choice, instead of a very poor description of wind variability

\footnotetext{
${ }^{4}$ One of the main features of this model is the soft-linking between an LTPM with a computable general equilibrium model. The macroeconomic aspects of renewables penetration are beyond the scope of our study and so we focus here on the LTPM-part of the REGEN model.

${ }^{5}$ The residual load is calculated as the overall load minus the production from all VRE sources.

${ }^{6} 98 \%$ of GHG emissions reductions compared to 1990 levels and $80 \%$ RES penetration together with nuclear phase-out by 2022.
} 
(only $10 \%$ of this variability), they were able to obtain a much more satisfying description (65\% captured). On top of this representation of wind variability, the model includes an additional TS schematizing extreme-peak demand as well as minimum backup capacity constraints. This temporal representation allows for better assessment of power system sizing. Within this framework, authors obtained similar results as in [16] concerning the trade-off between the different mitigation technologies (wind power, nuclear power, CCS and gridextensions) [17]. A similar study was conducted by Schmid et al. for the European and MENA $^{7}$ power system with the LIMES-EU model [18]. Pfenninger et al. assessed several decarbonisation scenarios for the United Kingdom (UK) electricity sector until 2050 using the Calliope model with 550 time-slices (TS) each represented year. In their model, the UK was divided into 20 regions and the grid capacity limits were taken into account. They found that increasing VREs' share up to $70 \%$ would only lead to a small cost increase compared to the optimal scenario, but that higher VRE shares would require grid-scale storage options, more imports, or the installation of dispatchable renewables [19]. The performances of a fairly poor time-resolution TIMES model (12 TS), applied to the Belgian power system was assessed by Poncelet et al. comparing the results with those obtained with the help of an hourly ODM, with and without detailed technical constraints. They showed that for low shares of VREs (less than 25\%) the few technical details of the TIMES model were a major source of error, but that above a certain threshold of VRE penetration, this error saturated and the error caused by low temporal resolution became the most significant. For 50\% VRE penetration in the power mix, the error in the dispatch is more than $10 \%$, with an overestimation of VREs and base-load power plant production and an underestimation of dispatchable power plant output, finally leading to a $50 \%$ underestimation of the operational costs. The authors then compared different strategies to improve the TIMES model's temporal description either by increasing the number of TSs, choosing TSs representing different wind resource availabilities (low, medium and high), or choosing representative days following a method proposed by [20]. They showed through systematic analysis that increasing the number of TSs only had a slight effect, whereas choosing TSs that capture VRE variability was far more efficient. For instance, they obtained very good results with a 36 TS model featuring TSs representing the different wind resource availabilities [21].

Besides these studies, soft-linking between an LTPM and an ODM has been developed to deal with VREs' impacts on power systems.

One of the first approaches by Deane et al. [22] achieved a coupling between TIMES and PLEXOS applied to the 2020 Irish power system, and then used in [7] as a proof of concept, with an application to the evolution of the Italian power system security until 2030. Among the many interesting results provided by the ODM analysis (with PLEXOS) of the optimal generation portfolio obtained with the TIMES model, they showed that this optimal portfolio was not reliable enough when looking at loss of load probability, and that many gas plants were not generating at all through the year, which strongly questions their profitability. Nevertheless, the TIMES model employed in this study ${ }^{8}$ used a relatively poor temporal representation with only 12 TSs. Pina et al. explored low-carbon scenarios for Portugal until 2050 using a soft-linking between a TIMES model (with 288 TS) and EnergyPLAN, which checks the supply-demand balance for each hour of the year with the optimal capacities obtained using TIMES. Above a given threshold of RES curtailment, constraints on RES capacities are added into the TIMES model to limit their penetration. They simulated two

\footnotetext{
${ }^{7}$ Middle East and North Africa

${ }^{8}$ A TIMES model for the Italian power sector only called MONET.
} 
scenarios, one with no new Pumped Hydro Storage (PHS), so that the only storage in the power system was the current PHS installed in Portugal $(1 \mathrm{GW})$, and one with a new PHS up to $4.3 \mathrm{GW}$. This second scenario never showed more than $2 \%$ VRE curtailment and thus did not need any iteration to meet the UCP requirements, whereas the first scenario needed 135 iterations. This demonstrates that the suitability of LTPM may depend on the assumptions made when high RES scenarios are simulated [23]. A soft-linking between a multi-objective LTPM with 7 TSs and an hourly dispatch simulation was also carried out by Zhang et al. for the Tokyo area in Japan. They studied least-cost pathways as well as least- $\mathrm{CO}_{2}$ emissions pathways until 2030 for different assumptions on nuclear evolutions. One of their results is the trade-off between coal and gas depending on the objective and improved integration of VREs (i.e. less curtailment is observed) with more gas and less coal since gas plants are more dispatchable [24].

Finally we present some studies which directly integrate some short-term dynamic features of power systems in LTPM.

Spiecker et al. have proposed this kind of integrated LTPM for assessing VRE penetration in the European power system (with a focus on Germany) for different demand scenarios and taking into account the stochastic behavior of VREs. Some typical ODM features were added as constraints on long-term optimization (reserve requirements divided into spinning and nonspinning reserves, startup costs, part load operations). Within this framework, it was found that penetration of renewables would reduce the number of load hours for dispatchable technologies, typically gas-fired plants, and also for some VREs, typically solar PV [25]. These results were confirmed by a mixed LTP-OD model developed by Koltsakis et al. and applied to the Greek power system evolution until 2030. The technical constraints included in the model make it possible to very precisely depict the reserves, ramping and startup requirements of thermal power plants and their associated costs. The optimal dispatch submitted to these technical constraints is performed every hour of one average day for each month of each investment period [26]. Welsch et al. have used the OSeMOSYS model with only 12 TSs to assess a renewables penetration scenario until 2050 in Ireland and showed that adding technical constraints (reserve requirements, ramping and cycling constraints for thermal power plants) significantly improved the results compared with a more detailed ODM. Moreover, using over-simplified models for assessing low-carbon scenarios ought to lead to an overestimation of VRE contribution and an underestimation of new capacity requirements, especially those that could most easily play a backup role, and thus of investment levels [27]. Komiyama et al. used a highly temporally detailed model with a 10minute resolution to analyze different nuclear and GHG mitigation scenarios until 2050. As well as the very accurate time representation, the model includes many technical constraints, such as minimum and maximum installable capacity, minimum production from thermal power plants, ramping constraints, and capacity reserves requirements. This model is particularly suitable for assessing the role of storage batteries for solar PV integration purposes [28]. Bertsh et al. modeled the European power system with the DIMENSION model, which integrates ramping constraints as well as different flexibility options that can meet these constraints. Moreover, the capacities of the investment model are fed into an hourly dispatch model to check the supply-demand balance more accurately. The goal of the authors was to give insights into the need for new market designs in order to remunerate the necessary backup dispatchable capacities accompanying VRE penetration. They showed that there was no need for flexibility incentives, since the low investment costs of open cycle gas turbines (OCGT) mean that they should naturally be installed for adequacy and backup purposes in scenarios with high shares of VREs. They would also provide the required 
flexibility as a by-product [29]. Finally, an approach based on a thermodynamic description of electromagnetism laws, which consists in assessing kinetic and magnetic energies embodied in the power system through the calculation of two indicators, illustrating the system's ability to tackle a supply-demand mismatch, was proposed in [30]. The calculation of these indicators was combined with a TIMES model which enabled addressing the long-term evolution of power system stability [31]. This approach was used to assess the French Reunion Island's commitment to energy independency by 2030, with a power sector relying only on RES [32], and then improved to include DSM [33] and storage technologies [34]. It was assessed that 50\% VRE penetration in the Reunion Island power system could be reached without jeopardizing kinetic reserves, which is above the $30 \%$ penetration limit currently included in the French law for insulated territories.

From this state-of-the-art, several conclusions can be drawn:

- Despite the different approaches, families of models and assumptions, some conclusions are similar regarding RES or VRE penetration, i.e. the need for flexible backup capacities, the reduced availability factor of thermal power plants, and the increasing level of VRE curtailment as their share increases, which can be alleviated by installing more storage capacities, applying demand-side management, or extending the power grid.

- Every approach has strengths and weaknesses: standard LTPMs lack some power system technical features leading to an underestimation of VRE impacts; soft-linking between an LTPM and an ODM requires maintaining two different models and raises unobvious questions concerning the iteration process between both models; and LTPMs integrating more detailed technical constraints similar to those existing in ODMs are limited by time calculations or the need for accurate and coherent data.

- The best strategy for tackling VRE penetration issues in LTPMs does not always seem to be to increase the number of TSs, but rather to adequately choose a limited but representative number of TSs, as stated by [21].

- Whatever the approach employed, there is generally a lack of investigation into the very short-term balance (seconds and minutes) for the simple reason that these timescales are not attainable in LTPMs (or ODMs). To our knowledge, the single approach that enables reconciling this very short-term dynamic with the long-term analyses performed by LTPMs, is the one proposed in [30] and applied to the Reunion Island.

\subsection{Approach and purposes of the present study}

In this study, we explore different levels of RES penetration in the French power system, from $40 \%$ to $100 \%$ by 2050 , with intermediate targets consistent with current laws on RES penetration in 2020 and 2030, and on nuclear production limitations after 2025 [4]. Hence we aim to extend the debate from the simple question "is a $x \%$ renewable power system feasible?" to a description of possible interplays between investment and operation decisions, and their evolution over time. For this purpose, we use a bottom-up, long-term investment planning model from the MARKAL-TIMES family [35], well suited for the dynamic evolution assessment on a long period of several decades, that we have improved with:

- TS resolution enabling us to capture, at least partly, demand as well as VRE variability as shown in [21];

- The disaggregation of power production technologies allowing us to capture the need for peak and extreme-peak power plants in the power system. This idea was suggested in [14, Sec. 5.5] but to our knowledge never used to assess RES penetration in power systems; 
- Combined representation of demand elasticity, demand-response technologies, storage technologies and interconnections to assess the interplay between all these flexibility options. Such a combination of flexibility options was only considered in very few studies, e.g. the role both of storage technologies and load-savings was assessed in [28] but not the contribution from interconnections or demand-response technologies; the study [29] gathered many flexibility options among which detailed demand-response options, but did not consider interconnections or elasticity of demand. None of the other studies reported in the state-of-the-art have assessed the role of demand-side options to cope with VRE variability.

We also couple our LTPM with the thermodynamic approach described in [30], which was never applied to a large-scale power system, to give:

i. The impact of different levels of RES penetration on those reserves and thus, on the reliability of the studied power system;

ii. An analysis of the levers that could result in an increase in power system reliability.

Altogether these features allow us to assess under which conditions the French power system could evolve from a low-carbon nuclear-based power system to another low-carbon power system relying on a completely different production paradigm.

Note that France currently provides kinetic energy to the whole synchronized European power system and thus helps stabilize it. In this respect, studying RES penetration in the French power system is of interest not only for national policy issues but also for its implications on other European power systems. Moreover, few RES penetration studies have been done of France, and to the author's knowledge, none based on an LTPM ${ }^{9}$.

We show that the penetration of RES in the French power system involves transforming the way the power system is operated. First, it requires new flexibility options, with the greatest contributions coming from load flexibility (reduction and postponing) and imports. Contrary to other studies we find only a small contribution from storage technologies. Second, there is a need for dispatchable power plants for back-up purposes, although this raises a financial question since they are likely to produce very little power. Finally, the French power system's ability to handle the supply-demand mismatch could be jeopardized with an increased share of RES if no technologies dedicated to this issue are installed.

The first part describes our model and the main assumptions used to conduct this study; the second part presents our results as well as a technical and economic analysis; the last part gives some conclusions, discusses the limitations of this study and points to future research likely to be of interest on this topic.

\section{METHODOLOGY}

\subsection{The reference energy system}

We use a model from the TIMES model family to assess the implications of RES penetration in the French power system. This kind of model allows a detailed representation of an energy system while giving a cost-optimal path for the evolution of this system, respecting policy, environmental and technical constraints [35]. In our case, we model mainland France and power exchanges with neighboring countries.

The technical representation of the power system consists of 30 existing technologies and 89 new technologies in order to describe the wide diversity of existing power plants in operation,

\footnotetext{
${ }^{9}$ A recent study used an hourly dispatch model for assessing high RES penetration levels (up to 100\%) in the French power system in $\mathbf{2 0 5 0}$ but it did not perform the full trajectory optimization from today to the horizon [36].
} 
or that could be in operation in the future, in France. The reference energy system used in this study is depicted on the diagram in Figure 1. Fossil, uranium, biomass resources and renewable flows of energy are consumed by power plants which produce electricity injected into the grid and generate $\mathrm{CO}_{2}$ emissions, either into the atmosphere or possibly into sinks if they are equipped with capture technology. Electricity can be converted into lower voltage and then consumed by the different demand sectors or consumed directly. It can also be imported and exported from and to other countries through existing or new interconnections. Demand response and storage technologies can be installed and participate in the supplydemand equilibrium.

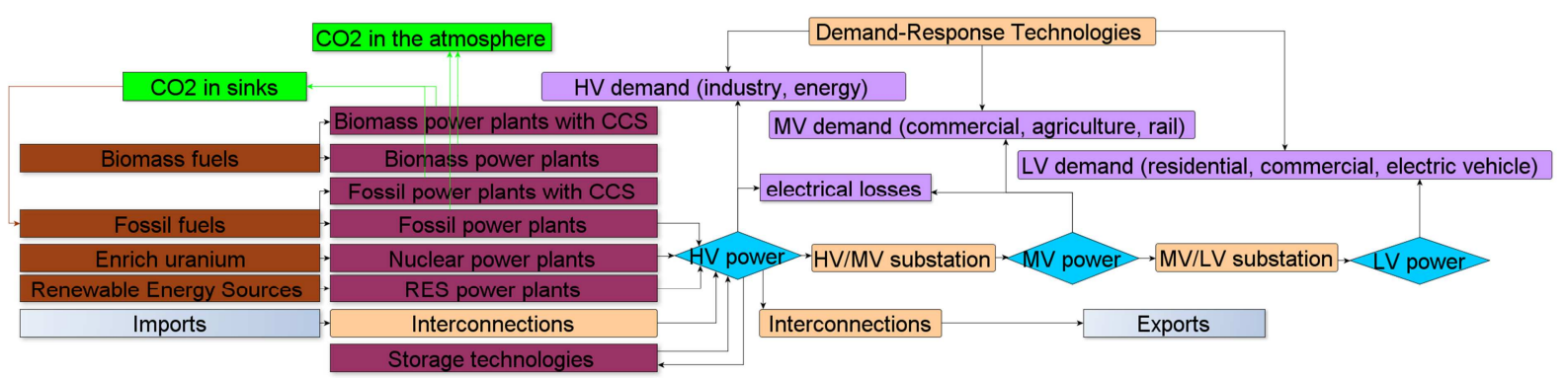

Figure 1. Schematic diagram of the reference energy system used in this study

\subsection{The temporal resolution of the model}

Figure 1 is a highly schematic description of the reference energy system combining existing and new technologies. In the model, the existing power system is represented with load and production calibrated on 2012 data. The model can then invest in new technologies to meet a future load input scenario with the objective of minimizing the overall cost of the energy system with the assumption of perfect foresight. In this study, the time horizon is 2050 and the time period of nearly forty years between 2012 and 2050 is divided into thirteen yearly periods of several years. Each yearly period is then divided into seven seasonal periods: six monthly periods, plus one that represents a potential winter week with low solar and wind production as well as restrictions on imports. Each seasonal period is split into two typical days, one representing working days and the other weekends. Finally, each typical day is divided into six hourly periods (two for the night, two for the morning, one for the afternoon and one corresponding to peak demand). This temporal resolution can capture some characteristics of power production, for example the seasonal variability of renewables, as well as part of the load variability (see Figure 2 for a diagram of this temporal description). Note that although our model captures some seasonal, weekly and daily variability, it does not perform the full chronological simulation. To do so would either require using $8760 \mathrm{TSs}$, which would be very time-consuming, or performing the full dispatch using a postoptimization tool ${ }^{10}$.

\footnotetext{
${ }^{10}$ This is what is done in the SWITCH model for example [15].
} 


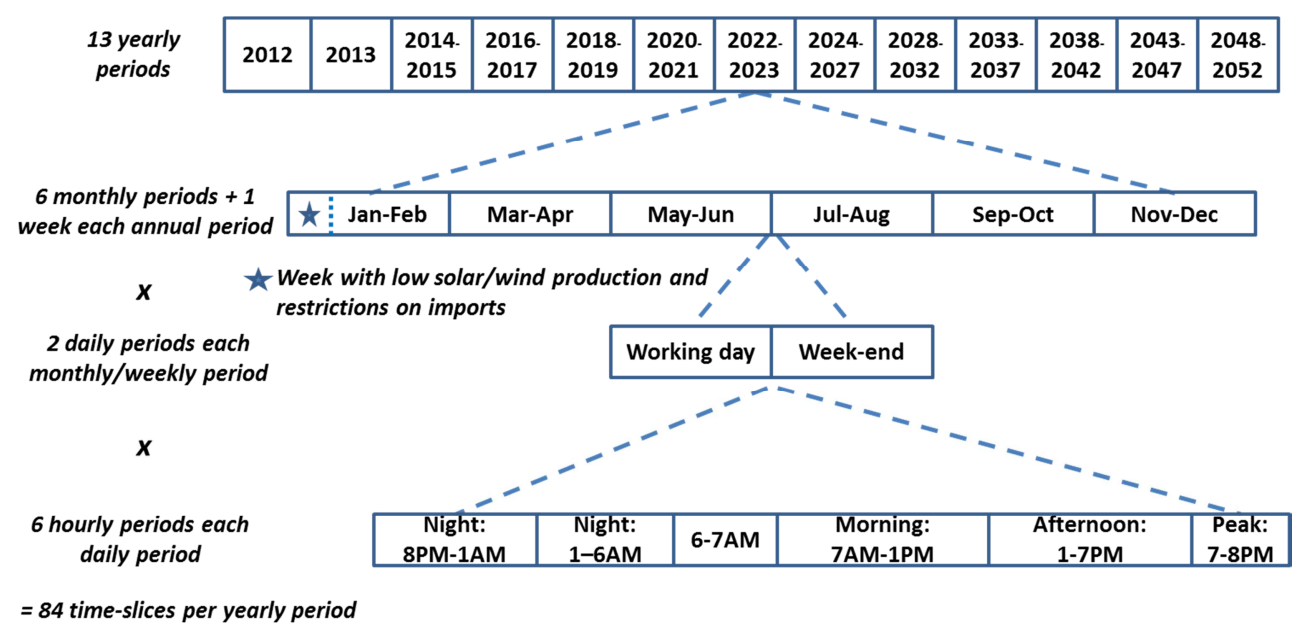

Figure 2. Temporal description used in the model

Despite the temporal resolution, this kind of model may neglect the role played by peak power plants, since it picks the technologies that satisfy demand with the best cost/efficiency ratio for each time-slice of each yearly period. To overcome this drawback, we disaggregate each dispatchable power production technology into six processes to represent the typical power curve, comprising base load, semi-base load, peak and extreme peak production (see Figure 3). We then add specific constraints to force the model to use the semi-base, peak and extreme-peak processes for a minimum number of hours each year to satisfy demand.

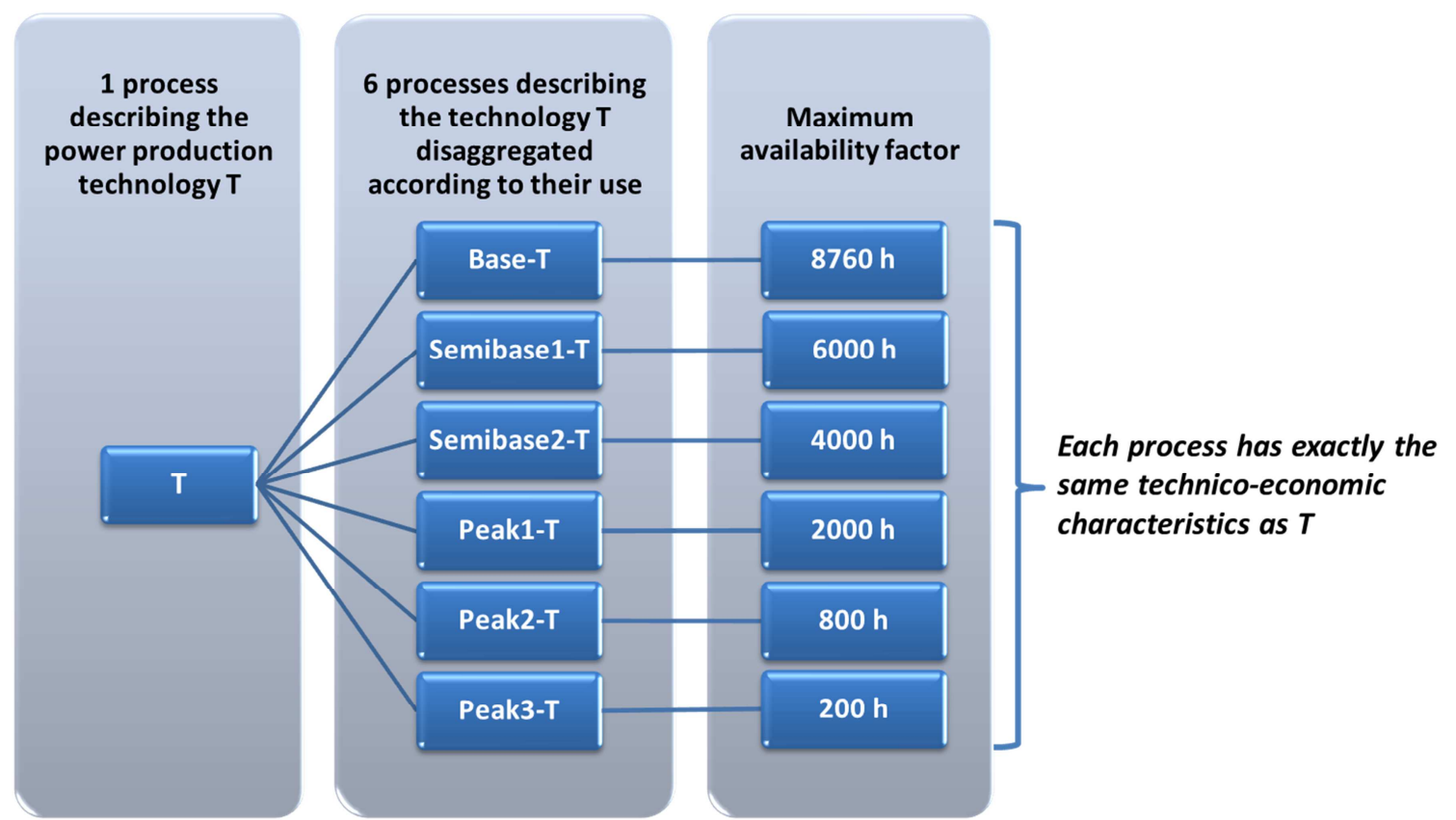

Figure 3. Disaggregation of each dispatchable power plant into six processes for a better representation of the production curve

To complete this energy representation of the supply-demand balance, a peak load factor forces the model to install more capacities than necessary to meet the peaking demand (see Figure 4). This factor represents the power system sizing required to meet an extreme-peak load that would not be captured by the model's temporal resolution, and to deal with power plant breakdowns and maintenance. 


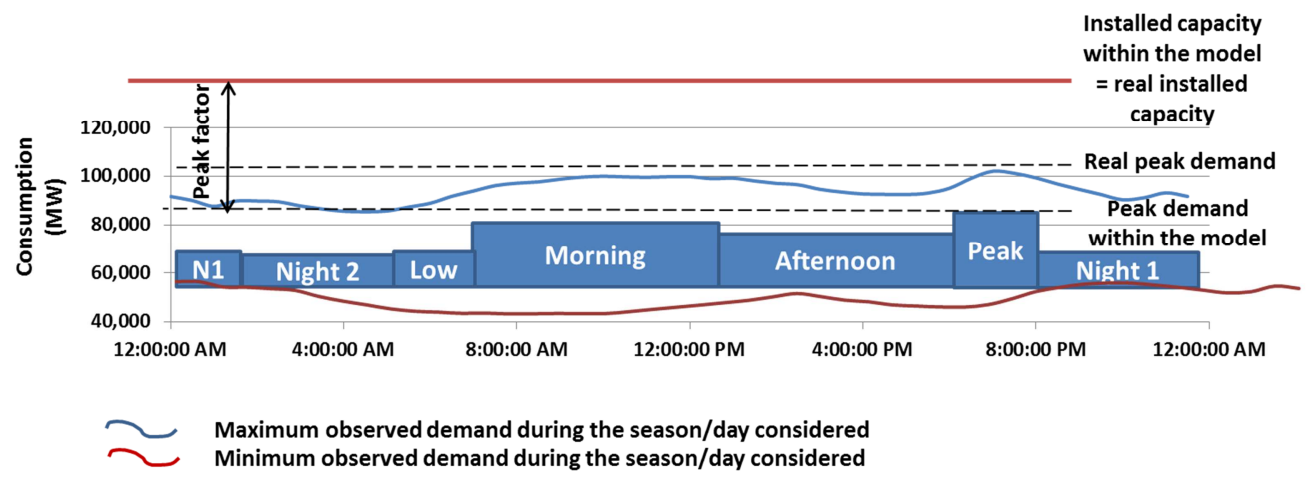

Figure 4. Illustration of the peak factor on a winter's day

Finally, whatever the temporal resolution of a prospective model, it cannot be sufficiently detailed to capture the short-term dynamics of power systems: for example, primary frequency control involves timescales of the order of a few tens of seconds. In order to make long-term energy planning models consistent with these short-term dynamics, we developed two indicators, related to kinetic and magnetic reserves, which depict the power system's ability to deal with a sudden disturbance. They are based on a thermodynamical representation of power systems, which enables the modeler to aggregate the power plants constituting the studied power system into a one-loop circuit. The magnetic reserve represents the energy embodied in coil windings all along the grid, and ensures power transmission through the grid. The kinetic reserve comes from the rotation of turbines connected to the grid and compensates for unbalanced power exchanges before any action can be taken by the operator to balance the power system. Within this representation, the evolution of kinetic and magnetic reserves can be calculated simply based on knowledge of the connected power plants at each time-slice of each period. This approach was described in detail in [37] and has been used for several studies on RES penetration in the Reunion Island power system [31], as well as for studying different scenarios on nuclear power in mainland France [38].

\subsection{Modeling renewable energy characteristics}

In order to explore very high levels of RES penetration in the French power system, we model a wide range of technologies based on these energies. Existing RES-based power plants include onshore wind, solar PV panels (ground-based and roof-based), hydro power plants (run-of-river and large dams), and biomass power plants (solid biomass, biogas or municipal waste in cogeneration plants or power-only plants). New power plants also include offshore wind, ocean power plants (wave energy and hydrokinetic), and geothermal power plants. Of these technologies, wind, solar and ocean power plants are known as variable renewable energies (VREs), as their output cannot be controlled by an operator. To represent this characteristic of VREs, we use production patterns for solar and wind power plants based on the production output in 2012 and taken from RTE half-hour data [39]. We then aggregate these production data to match the temporal precision of our model as shown on Figure 5. As we are using a deterministic model, we do not consider different patterns for output productions. As a result, we fail to capture the inter-annual variability of VREs. However, this drawback is at least partially overcome by the representation of a hypothetic week during which solar and wind production equal the minimum production observed during $2012^{11}$. In addition, imports are also set to zero during this week and demand is high. In high-level RES

\footnotetext{
${ }^{11}$ In the following this week is called Cweek for "constrained week".
} 
penetration scenarios, this week forces the system to install other power plants to compensate for this very low production.

Note that in our model, offshore wind power production is considered to follow the same pattern as that of onshore wind, but with a higher annual availability factor.

Since ocean power plants have not yet been installed in France (with the exception of "La Rance" tidal energy power plant), we do not have accurate data on their output production throughout the year. For this reason, we consider constant production from these power plants in our model. For hydro power plants, we also consider seasonal availability factors.

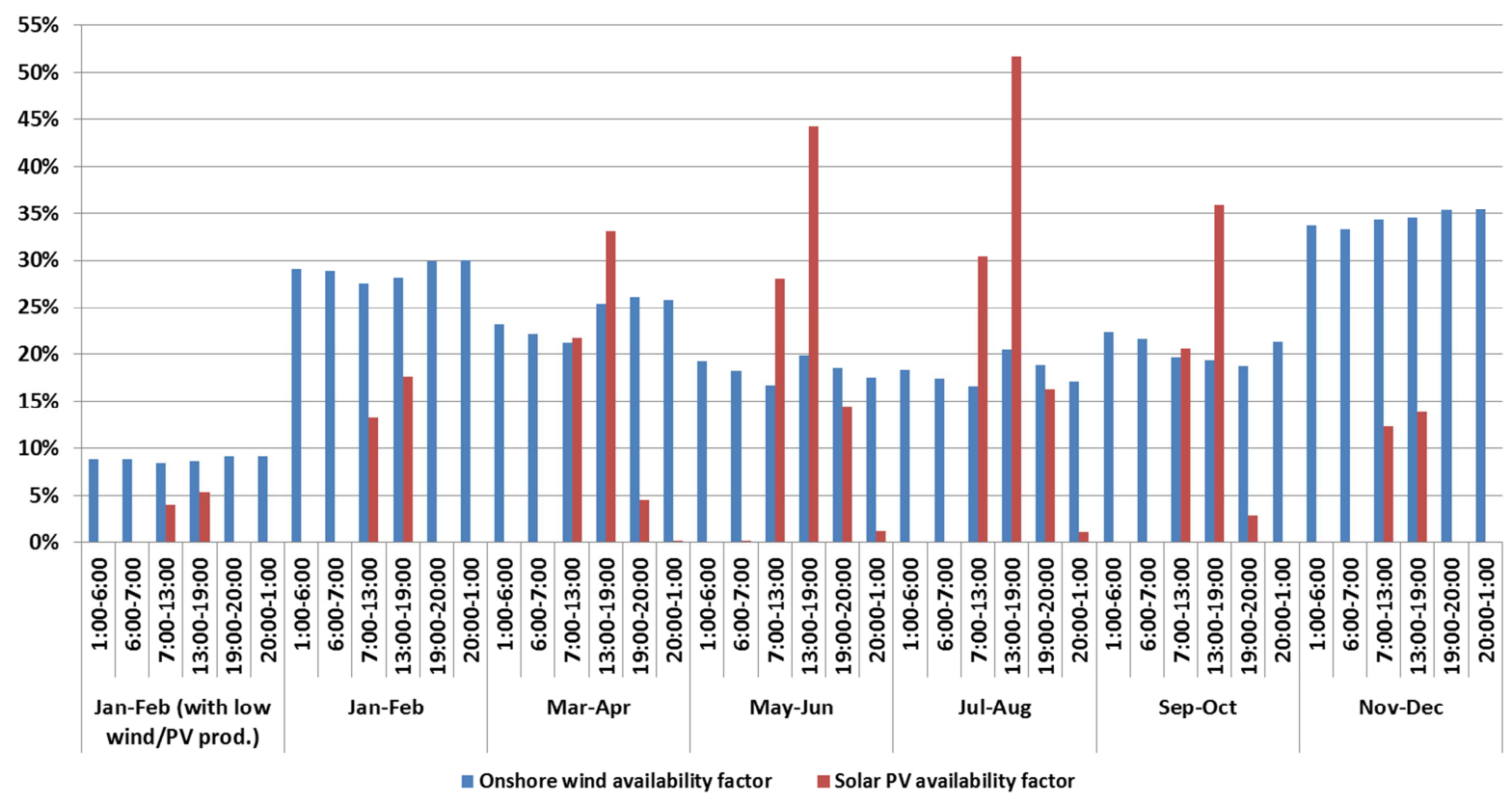

Figure 5. Onshore wind and PV production for each time-slice of the year

RES participate in the peak load factor according to their availability factor during the peak load period (corresponding to the winter peak at 19:00): dispatchable RES power plants contribute entirely to this factor whereas solar PV does not contribute at all (solar-based power plants do not produce electricity during the evening in winter); other VREs, like wind turbines or marine renewable energy, participate in this factor to the extent of their availability factor during the winter peak period ( $28 \%$ for onshore wind, $50 \%$ for offshore wind and $40 \%$ for ocean energy). In some scenarios (variants $v 2$ ), we analyze the amount of additional capacity required for back-up reserve purposes in case VREs are supposed not to participate in the peak factor (see next section).

In this study, we consider that VREs do not contribute to kinetic and magnetic reserves since they are connected through electronic devices [31]. In our case, this means that we implicitly consider that power systems should be able to deal with hazards without relying on VREs, whose production is not completely predictable and cannot be adjusted to demand. Nevertheless, we also test a case with wind turbines providing kinetic reserves (see 3.6, Figure 21).

\subsection{Modeling flexibility options}

In this study, on top of the multiple power supply technologies, we integrate four other flexibility options into the model. Two are related to load: demand elasticity has been introduced to simulate the impact of an electricity price increase on energy demand levels; and two Demand-Response technologies (DR) contribute either to the peak load factor (sub- 
hourly $D R$ ) or to the supply-demand balance during the day (hourly $D R$ ) following the methodology described in [40]. The sub-hourly DR represents devices that can be stopped for a time shorter than the duration of the time-slices, typically less than one hour, for example refrigeration, heating, cooling and ventilation. The hourly DR represents devices that can be postponed from one time-slice to another on the same day without reducing their overall consumption, for example water heaters, some industrial processes and electric vehicle loading. Other flexibility options represented in the model are storage technologies: pumped hydroelectric storage (PHS), which is already well developed in France, advanced adiabatic compressed air energy storage (AA-CAES), and a technology called "other storage", which could represent e.g. hydrogen storage or thermal energy storage. Here we only represent "long-term" storage technology and not technologies that can deliver power for one hour or less, like some batteries ${ }^{12}$ or flywheels, because of the time-resolution of our model. The last technology option is the new interconnections, either in alternative current (AC) or direct current (DC).

One of the main features of long-term planning models such as the one used in this study is the exploration of the long-term evolution of energy systems with a given set of future available technologies, demand scenarios, and technical, economic, environmental and political constraints. Here we explore the role of some flexibility options in contrasted RES penetration scenarios, as well as the trade-off between each of these options according to different assumptions on their availability.

\subsection{Costs and prices assumptions}

Technology cost assumptions are mainly described in [42]. Since this study, PV and wind power plant costs have been updated to reflect their sharp decrease in recent years. For PV, we consider investment costs from [42] and for wind power from [43], [44]. We also give the model the possibility to invest in new interconnection capacities taking investment costs from [45]. Those costs are based on the new France-Spain interconnection (€700 M for $1.4 \mathrm{GW}$ in $\mathrm{DC}$ which is about eight times the cost of AC interconnections). The investment costs of new storage technologies are taken from [46]. Finally, the investment costs of RES, interconnections and storage technologies are summed up in Table 1. Note that we do not consider any evolution in interconnections and storage technologies costs in this study.

Table 1. PV, wind, interconnections and storage investment costs from 2013 to 2050

\begin{tabular}{|lrrrr|}
\hline \multicolumn{1}{c}{ Run-of-river $^{\mathbf{1 3}}$} & $\mathbf{2 0 1 3}$ & $\mathbf{2 0 2 0}$ & $\mathbf{2 0 3 0}$ & $\mathbf{2 0 5 0}$ \\
& $3,366-4,382$ & $3,366-4,382$ & $3,366-4,382$ & $3,366-$ \\
& & & & 4,382 \\
\hline Hydro dams & 2,850 & 2,850 & 2,850 & 2,850 \\
\hline Biomass power plants $^{\mathbf{1 4}}$ & $3,697-3,902$ & $3,337-3,754$ & $2,881-3,552$ & $2,149-$ \\
& & & & 3,181 \\
\hline Biogas power plants & 2,646 & 2,534 & 2,381 & 2,103 \\
\hline Municipal waste power plants & 4,268 & 4,268 & 4,268 & 4,268 \\
\hline Geothermal power plants & 5,907 & 5,588 & 5,161 & 4,403 \\
\hline Ocean wave energy & 6,000 & 5,638 & 4,913 & 3,887 \\
\hline Ocean hydrokinetic turbine & 5,200 & 4,900 & 4,300 & 3,438 \\
\hline
\end{tabular}

\footnotetext{
${ }^{12}$ Some batteries have longer operational time constants, like NaS batteries, not represented in our model.

${ }^{13}$ Costs of run-of-river power plants depend on their size; in the model this technology has been disaggregated into three versions (small, medium and large).

${ }^{14}$ In the case of biomass power plants, costs depend on the technology used to produce electricity (steam turbine, gas turbine, internal combustion or cogeneration).
} 


\begin{tabular}{|lrrrr|}
\hline Onshore wind & 1,500 & 1,403 & 1,305 & 1,110 \\
\hline Offshore wind & 2,590 & 2,111 & 1,632 & 1,425 \\
\hline Roof solar PV & 3,034 & 2,220 & 1,480 & 1,110 \\
\hline Ground solar PV & 1,628 & 1,110 & 740 & 518 \\
\hline AC interconnection & 62.5 & 62.5 & 62.5 & 62.5 \\
\hline DC interconnection & 500 & 500 & 500 & 500 \\
\hline PHS & 2,835 & 2,835 & 2,835 & 2,835 \\
\hline AA-CAES & 1,200 & 1,200 & 1,200 & 1,200 \\
\hline Other storage & 1,500 & 1,500 & 1,500 & 1,500 \\
\hline
\end{tabular}

Fossil fuel prices are then taken from the WEO 2013 "current policies" scenario [47].

\subsection{Technology potentials and installation pace}

Today, the capacity of all of the interconnections between France and neighboring countries is $15 \mathrm{GW}$ for exports and 9.5 GW for imports [48]. According to [48] current interconnections, projects should lead to an increase of $4.6 \mathrm{GW}$ for imports and $3.6 \mathrm{GW}$ for exports before 2020. For the longer term, we use the values proposed in the "reference" scenario of [48] as an upper limit for 2030 and those proposed in the "nouveau mix" scenario, which is a more ambitious scenario in terms of RES penetration from the same source, for 2050. Import and export potentials for 2030 and 2050 as well as the potentials of the different forms of RES and storage technologies are summed up in Table 2. In this table, we also provide the availability factors used in this study for these technologies. RES and storage potentials come from [49].

Table 2. RES, interconnections and storage potentials and availability factors considered in this study

\begin{tabular}{|c|c|c|c|}
\hline Technology & $\begin{array}{l}\text { Potential in } \\
2030\end{array}$ & $\begin{array}{l}\text { Potential in } \\
2050\end{array}$ & Availability factor / storage efficiency \\
\hline Imports & $20 \mathrm{GW}$ & $24 \mathrm{GW}$ & $84 \%$ \\
\hline Exports & $25 \mathrm{GW}$ & $29 \mathrm{GW}$ & $84 \%$ \\
\hline Onshore wind & $34 \mathrm{GW}$ & $40 \mathrm{GW}$ & $23 \%$ \\
\hline Offshore wind & $12 \mathrm{GW}$ & $30 \mathrm{GW}$ & $40 \%$ \\
\hline PV & $33 \mathrm{GW}$ & $65 \mathrm{GW}$ & $14 \%$ \\
\hline $\begin{array}{l}\text { Hydrokinetic } \\
\text { energy }\end{array}$ & $1 \mathrm{GW}$ & $3 \mathrm{GW}$ & $40 \%$ \\
\hline Wave energy & $0.2 \mathrm{GW}$ & $10 \mathrm{GW}$ & $40 \%$ \\
\hline Solid biomass & $13.8 \mathrm{TWh}$ & 15.1 TWh & Depends on technology used to produce \\
\hline Biogas & $14,3 \mathrm{TWh}$ & $15.1 \mathrm{TWh}$ & electricity \\
\hline Municipal waste & $12.8 \mathrm{TWh}$ & $13.9 \mathrm{TWh}$ & \\
\hline Geothermal energy & $1.2 \mathrm{TWh}$ & $4.6 \mathrm{TWh}$ & $85 \%$ \\
\hline Hydro & \multicolumn{2}{|c|}{ Current production } & $\begin{array}{l}23 \% \text { for large dams } \\
48 \% \text { for run-of-river }\end{array}$ \\
\hline PHS & $1 \mathrm{GW}$ & $1.5 \mathrm{GW}$ & $45 \% / 75 \%$ \\
\hline AA-CAES & $0.5 \mathrm{GW}$ & $0.5 \mathrm{GW}$ & $45 \% / 70 \%$ \\
\hline Other storage & $1 \mathrm{GW}$ & $3 \mathrm{GW}$ & $45 \% / 70 \%$ \\
\hline
\end{tabular}

Besides these potentials, we also consider assumptions on the upper limits of the pace of installation for the different technologies in order to avoid massive and unrealistic investments over a short period. These hypotheses are shown in Table 3.

Table 3. New capacity installation paces for the different technologies 


\begin{tabular}{|ll|}
\hline \multicolumn{1}{|c|}{ Power plant type } & \multicolumn{1}{c|}{ Upper limits of installation pace } \\
& $\begin{array}{l}1.6 \mathrm{GW} \text { in 2016 (Flamanville nuclear power plant under } \\
\text { construction), 0 GW from } 2018 \text { to 2020, } 1.6 \mathrm{GW} \text { in } 2022 \text { and } \\
2025,1.6 \mathrm{GW} / \mathrm{y} \text { from } 2025 \text { to } 2030 \text {, then } 3.2 \mathrm{GW} / \mathrm{y} \text { after } 2030\end{array}$ \\
\hline Fossil and RES (except hydro) & $\begin{array}{l}\text { For each different technology: } 1 \mathrm{GW} / \mathrm{y} \text { until } 2015,2 \mathrm{GW} / \mathrm{y} \text { from } \\
2015 \text { to } 2030, \text { then } 3 \mathrm{GW} / \mathrm{y} \text { from } 2030 \text { to } 2050\end{array}$ \\
\hline Interconnections & Fixed until 2020, then $1 \mathrm{GW} / \mathrm{y}$ from 2020 to 2050 \\
\hline
\end{tabular}

\subsection{Demand assumptions}

Concerning the evolution of demand, we use data from the "reference" scenario produced by the French transmission system operator RTE [48] that we extend beyond 2030, considering a similar annual growth rate as the 2020-2030 period. Demand is considered elastic with elasticity values taken from [50] but cannot go below the values of the "nouveau mix" scenario by [48], which is considered as a lower limit in terms of demand reduction in our study. Demand assumptions are summed up in Table 4. In this table, the total corresponds to the overall demand without electricity losses. Losses are integrated in our model in such a way that they account for $8.3 \%$ of net demand [43]. Taking these losses into account, demand is about 495 TWh in 2012 and 519 TWh in 2050

Table 4. Evolution of demand for each sector and elasticity assumptions

\begin{tabular}{|lrrrrrrrr|r|}
\hline $\begin{array}{l}\text { Sector } \\
\mathbf{2 0 1 2} \text { demand } \\
\text { (TWh) }\end{array}$ & Residential & Commercial & Industry & Agriculture & Energy & Railway & EV/HV & Total \\
\hline $\begin{array}{l}\mathbf{2 0 3 0} \text { demand } \\
\text { (TWh) }\end{array}$ & 161 & 133 & 117 & 8.8 & 24 & 13 & 0.1 & $\mathbf{4 5 7}$ \\
\hline $\begin{array}{l}\mathbf{2 0 5 0} \text { demand } \\
\text { (TWh) }\end{array}$ & 161 & 145 & 117 & 4.0 & 12 & 16 & 7.5 & $\mathbf{4 6 2}$ \\
\hline $\begin{array}{l}\text { Elasticity } \\
\text { Upper }\end{array}$ & -1 & 145 & 119 & 4.9 & 12 & 22 & 15 & $\mathbf{4 7 9}$ \\
$\begin{array}{l}\text { variation } \\
\text { with elasticity }\end{array}$ & $17 \%$ & $11 \%$ & $9 \%$ & 0.5 & -0.8 & 0 & 0 & 0 & NA \\
\hline
\end{tabular}

Since French DR potentials cannot be found in the literature, we make our own educated assumptions on these two kinds of DR for the different demand sectors, given in Table 5.

Table 5. Assumptions on DR potentials

\section{DR}

technology

Sub-hourly $\quad 2.5 \%$ of residential and commercial sector

DR

Hourly DR $2.5 \%$ of residential, commercial and industry sector demand and $12.5 \%$ of EV/HV demand

\section{Potential in 2050}

$10 \%$ of residential and commercial sector demand

$10 \%$ of residential, commercial and industry sector demand and $50 \%$ of EV/HV demand

The modeling methodology and the assumptions described above result in a rigorous representation of the French power system and its evolution until 2050. 


\section{SCENARIO ANALYSIS}

\subsection{General description of the scenarios}

In this study, we investigate the possible consequences of different RES penetration levels on the French power system using the model described above. In this part we analyze the results of six "reference" scenarios described in Table 6 as well as variants created from these scenarios.

A $\mathrm{CO}_{2}$ upper limit is implemented in each of the studied scenarios to avoid any evolution of the French power system that would lead to higher levels of $\mathrm{CO}_{2}$ emissions. For each period studied in our model, the French power system's $\mathrm{CO}_{2}$ emissions are constrained below 2012 levels (39 Mt). The law on energy transition currently being debated in France foresees reducing nuclear power production from $75 \%$ to $50 \%$ of overall production by 2025 [4]. We add a constraint on nuclear power production in every scenario except the Business-As-Usual (BAU) so that the model will build a future power system that respects this commitment. Except for the $B A U$ scenario, we also add RES penetration objectives for 2020 and 2030 from the same energy transition law, and complete them with RES penetration objectives for the period beyond 2030. The name of the scenario refers to the RES level in power production in 2050. We then add intermediate objectives with a maximum increase of $15 \%$ of RES in power production in five years. All of the scenarios listed below rely on the assumptions depicted in the former section. The calculation of final demand in a scenario, after reduction due to its elasticity, is based on the difference between the electricity price in this scenario compared to the $B A U$ scenario.

The comparison of these scenarios enables us to assess the impact of RES penetration on the French power system in terms of optimal power mix, required investments, power plant profitability, power production throughout the year, and kinetic reserves.

Table 6. Description of the "reference" scenarios used in this study

\begin{tabular}{|c|c|c|c|c|c|c|c|}
\hline Scenarios & Years & $\mathbf{B A U}$ & $\begin{array}{l}\text { 40RES } \\
2030\end{array}$ & $\begin{array}{c}\text { 60RES } \\
2050\end{array}$ & $\begin{array}{l}\text { 80RES } \\
2050\end{array}$ & $\begin{array}{l}\text { 90RES } \\
2050\end{array}$ & $\begin{array}{c}\text { 100RES } \\
2050\end{array}$ \\
\hline $\begin{array}{l}\mathrm{CO}_{2} \text { emissions } \\
\text { constraint }\end{array}$ & $\begin{array}{l}2012- \\
2050\end{array}$ & $\begin{array}{l}39 \\
\mathrm{Mt}\end{array}$ & $39 \mathrm{Mt}$ & $39 \mathrm{Mt}$ & $39 \mathrm{Mt}$ & $39 \mathrm{Mt}$ & $39 \mathrm{Mt}$ \\
\hline $\begin{array}{l}\text { Nuclear } \\
\text { production } \\
\text { constraint }\end{array}$ & $\begin{array}{l}2025 \text { and } \\
\text { after }\end{array}$ & NA & $50 \%$ & $50 \%$ & $50 \%$ & $50 \%$ & $50 \%$ \\
\hline \multirow{6}{*}{$\begin{array}{l}\text { RES penetration } \\
\text { objectives }\end{array}$} & 2020 & NA & $27 \%$ & $27 \%$ & $27 \%$ & $27 \%$ & $27 \%$ \\
\hline & 2030 & NA & $40 \%$ & $40 \%$ & $40 \%$ & $40 \%$ & $40 \%$ \\
\hline & 2035 & NA & $40 \%$ & $40 \%$ & $40 \%$ & $45 \%$ & $55 \%$ \\
\hline & 2040 & NA & $40 \%$ & $40 \%$ & $50 \%$ & $60 \%$ & $70 \%$ \\
\hline & 2045 & NA & $40 \%$ & $45 \%$ & $65 \%$ & $75 \%$ & $85 \%$ \\
\hline & 2050 & NA & $40 \%$ & $60 \%$ & $80 \%$ & $90 \%$ & $100 \%$ \\
\hline
\end{tabular}

On top of these contrasted RES penetration scenarios, we perform a sensitivity analysis on some assumptions described above. The different variants tested for this analysis are summed up in Table 7. 
Table 7: Variants from the "reference" scenarios

\begin{tabular}{|c|c|c|c|c|c|c|}
\hline Variants & BAU & $\begin{array}{l}\text { 40RES } \\
2030\end{array}$ & $\begin{array}{l}\text { 60RES } \\
2050\end{array}$ & $\begin{array}{l}\text { 80RES } \\
2050\end{array}$ & $\begin{array}{l}\text { 90RES } \\
2050\end{array}$ & $\begin{array}{l}\text { 100RES } \\
2050\end{array}$ \\
\hline $\begin{array}{l}\text { No week with low wind/PV } \\
\text { production (v1) }\end{array}$ & & & $\mathbf{X}$ & & & $\mathbf{X}$ \\
\hline $\begin{array}{l}\text { VREs do not participate in } \\
\text { peak load factor (v2) }\end{array}$ & $\mathbf{X}$ & $\mathbf{X}$ & $\mathbf{X}$ & $\mathbf{X}$ & & $\mathbf{X}$ \\
\hline $\begin{array}{l}\text { No imports of electricity in } \\
2050 \text { (v3) }\end{array}$ & & & & & & $\mathbf{X}$ \\
\hline No demand flexibility ${ }^{15}$ (v4) & & & & & & $\mathbf{X}$ \\
\hline High biomass potential (v5) & & & & & & $\mathbf{X}$ \\
\hline $\begin{array}{l}\text { Upper limits }(50 \% \& 30 \%) \text { on } \\
\text { VRE penetration (respectively } \\
\text { v6 \& v7) both with high } \\
\text { biomass potential }^{16}\end{array}$ & & & & & & $\mathbf{X}$ \\
\hline $\begin{array}{l}\text { Half of the imports contribute } \\
\text { to kinetic reserves (v8) }\end{array}$ & & & & & & $\mathbf{X}$ \\
\hline $\begin{array}{l}\text { Wind turbines contribute to } \\
\text { kinetic reserves (v9) }\end{array}$ & & & & & & $\mathbf{X}$ \\
\hline
\end{tabular}

The first two variants show the influence of more or less severe assumptions related to VREs' characteristics on the results. The third and fourth ones help us understand the role of some flexibility options in high RES penetration scenarios. Today, biomass is mainly used for cogeneration; the study by $\mathrm{ADEME}^{17}$ [49], from which we made our RES potential assumptions, considers that in the future biomass resources will be mainly used for heating, injected into the gas network, or as fuel for the transportation sector. Scenarios with a higher biomass potential (fifth variant) enable us to explore different ways of using biomass and better understand how this resource could contribute to the power supply. The reference biomass potentials and the high biomass potentials are given in Table 8 . The sixth and seventh variants question the potential role of an upper limit on VRE penetration in totally RES-based power systems in terms of reliability. Indeed, as explained in the former section, VREs do not contribute to kinetic reserves and so their penetration may jeopardize the power system. Finally, the last two variants are only used in the reliability analysis in section 3.6. For these two variants, we do not need to run the TIMES model again: we only change the assumptions used to calculate the kinetic reserves in the post-treatment calculation.

Altogether, 20 scenarios were simulated in this study to produce a comprehensive analysis of RES penetration trajectories in the French power system.

\footnotetext{
${ }^{15}$ This means no demand elasticity and no demand-response technologies available.

${ }^{16}$ In variants $v 6$ and $v 7$, the same high biomass potential as in variant $v 5$ was assumed because there were not enough RES potentials, considering the assumptions summed up in Table 2, for the model to meet demand with a constraint on VRE penetration.

${ }^{17}$ The French National Environment and Energy Management Agency
} 
Table 8 . Biomass potentials (Mtep) in the reference scenario and in the high potential variant ${ }^{18}$

\begin{tabular}{|lllllll|}
\hline \multicolumn{1}{|c|}{$\begin{array}{c}\text { Mtep } \\
\text { Year }\end{array}$} & Wood & Biogas & $\begin{array}{l}\text { Municipal } \\
\text { waste }\end{array}$ & Wood & Biogas & $\begin{array}{l}\text { Municipal } \\
\text { waste }\end{array}$ \\
\hline $\mathbf{2 0 1 2}$ & 0.42 & 0.33 & 2.30 & 0.42 & 0.33 & 2.30 \\
\hline $\mathbf{2 0 3 0}$ & 1.19 & 1.23 & 2.30 & 16.00 & 5.80 & 2.30 \\
\hline $\mathbf{2 0 5 0}$ & 1.30 & 1.30 & 2.30 & 17.10 & 8.80 & 2.30 \\
\hline
\end{tabular}

\subsection{Evolution of power production with RES penetration}

In Figure 6, we compare the evolution of the power mix in the different scenarios studied. In this figure exports are counted negatively whereas power plant production and imports are counted positively.

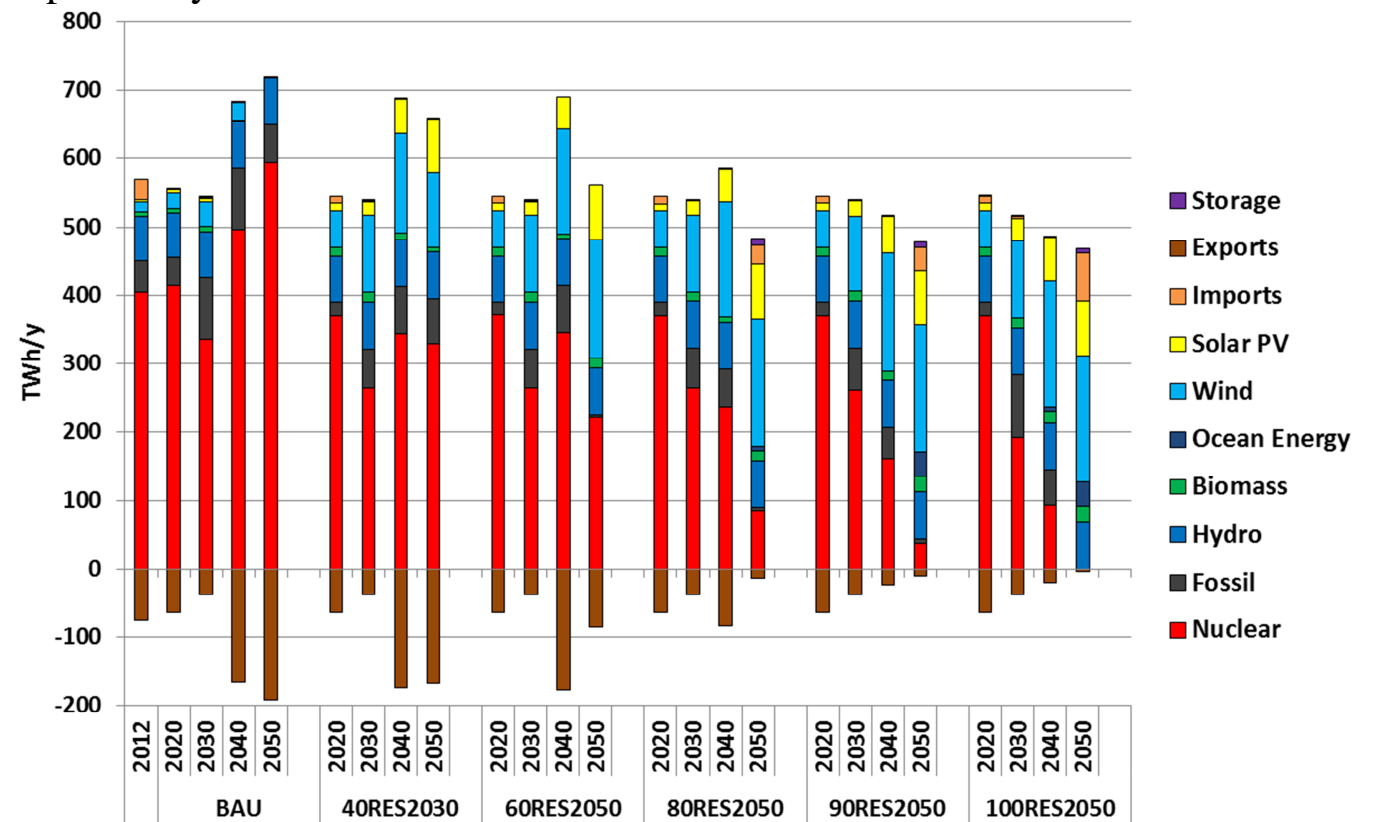

Figure 6. Evolution of the power mix in the six reference scenarios

Today, nuclear is the main source of power production in France, with more than $75 \%$ of overall production. In a $B A U$ scenario, the share of nuclear in power production could be reduced in 2030 to the benefit of fossil power plants. After 2030, nuclear power production increases again, while fossil and RES productions decrease. In this scenario, imports are negligible and exports follow nuclear power production, almost reaching $200 \mathrm{TWh}$ in 2050 thanks to new interconnections. Then, as RES penetration gradually increases, nuclear power and, to a lesser extent fossil fuels, are replaced mainly by wind and PV. In the $100 \%$ RES scenario, wind accounts for $40 \%$ of the overall production and solar PV for $17 \%$. Exports also decline with RES penetration, almost ceasing at 100\% RES penetration. Exports are strongly correlated to the nuclear power share. On the contrary, imports are greater for high levels of RES power production. Domestic production varies significantly between periods and scenarios: from 540 TWh in 2012, it increases to 718 TWh in 2050 in the $B A U$ scenario and

\footnotetext{
${ }^{18}$ In the reference scenarios biomass potentials directly correspond to the assumptions made in [49] for the power sector, whereas in the variant they correspond to the overall potential, for all sectors, from the same study.
} 
falls to $391 \mathrm{TWh}$ in the $100 \%$ RES scenario. The evolution of the power mix in the $100 \%$ RES variants is given in Figure 7.

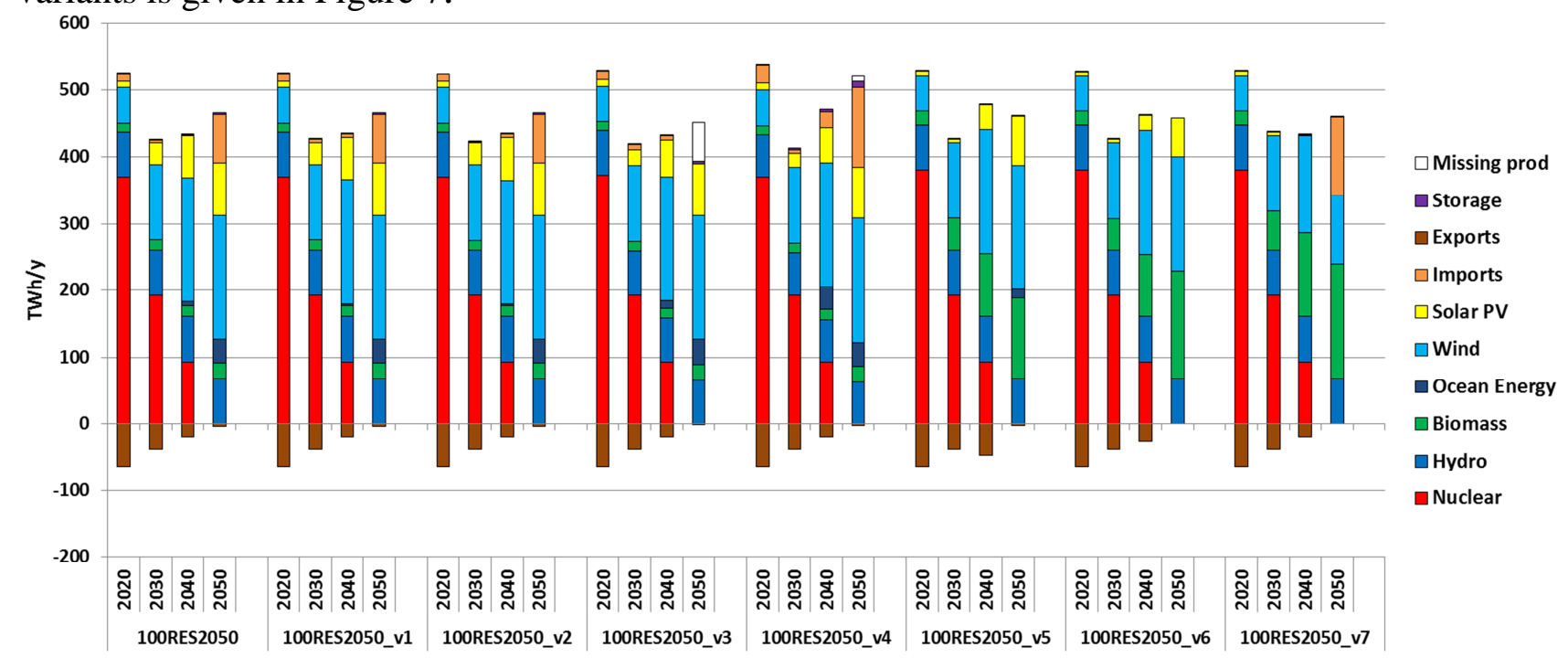

Figure 7. Evolution of the power mix in the $100 \%$ RES reference scenario and variants Note that the overall demand is not the same in the different scenarios because of the assumptions made on demand elasticity, which cause demand reduction, as seen on Figure 8.

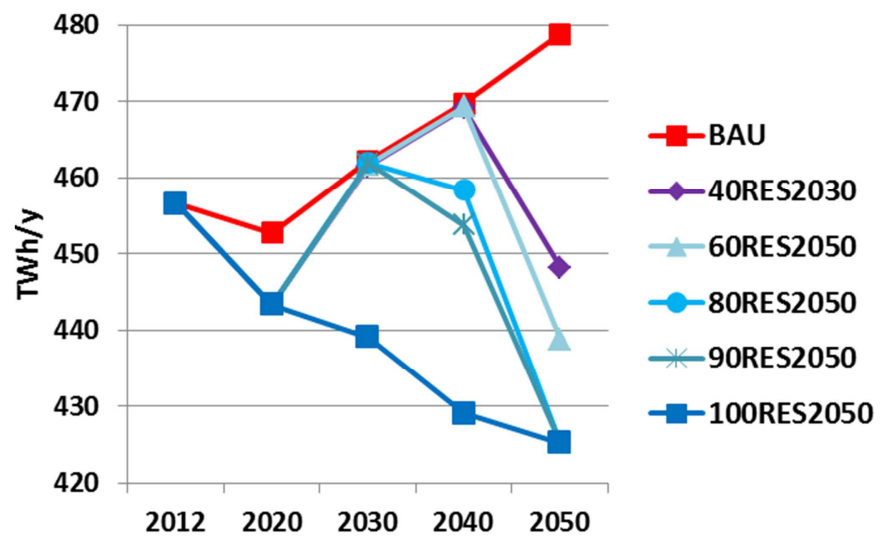

Figure 8. Evolution of overall demand from 2012 to 2050 in the six reference scenarios taking demand elasticity into account

In the $100 \%$ RES scenario, all of the elasticity potential is exploited. In the $80 \%$ and $90 \%$ RES scenarios, this potential is only fully exploited in 2050. Then, when RES penetration decreases, demand is reduced less, reflecting the electricity prices in the different scenarios.

\subsection{RES penetration induces massive installation of power plants and reduces the profitability of flexible power plants}

The differences in power production between the scenarios reflect both the installed capacity and the number of operating hours. Indeed, the availability factors of RES power plants are much lower than those of nuclear power plants. Moreover, RES penetration tends to cause the depletion of flexible power plants' availability factors as shown in Figure 9. 


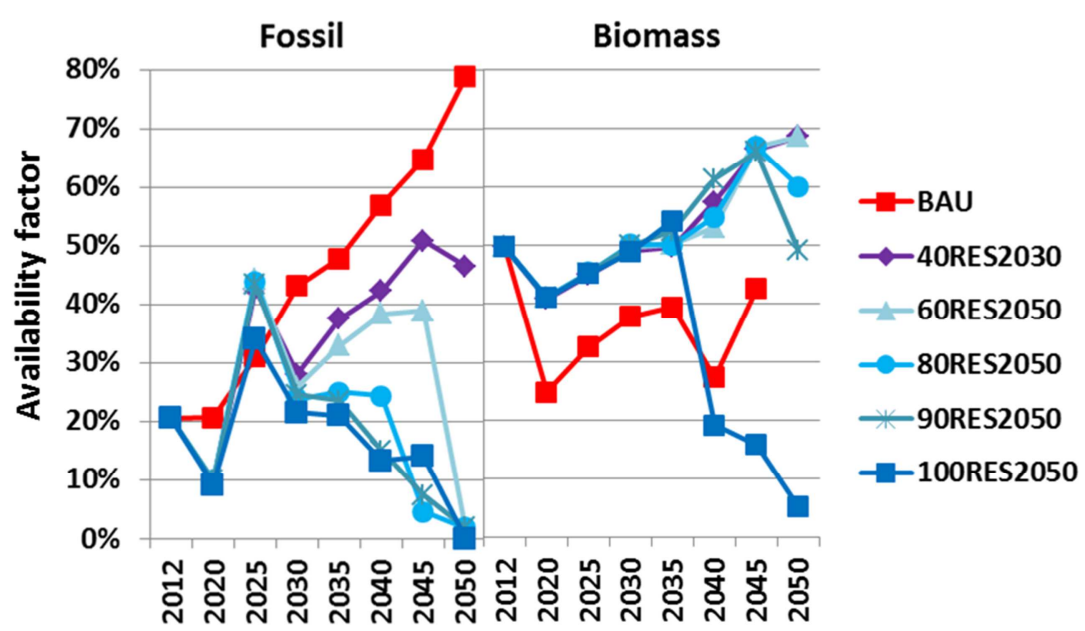

Figure 9. Evolution of power plants' availability factors for fossil (on the left) and biomass (on the right) from 2012 to 2050 in the six reference scenarios

The effect of RES penetration on the availability factors of flexible power plants is very clear for fossil power plants: the more RES power plants participate in power production, the fewer fossil power plants are used, reaching very low availability factors in 2050, when RES exceed $60 \%$ power production. This effect is a little more contrasted for biomass power plants: for up to $80 \%$ RES penetration, the biomass power plants' availability factor is higher than in the $B A U$ scenario, but in the $100 \%$ RES scenario it declines dramatically after 2040. Low availability factors raise the issue of the profitability of power plants. If they do not supply enough power throughout the year, they cannot cover their fixed costs. This is a common result concerning VRE integration impacts on power systems: VREs require flexible power plants that can be operated quickly when VRE production is low and demand is high. However, because of their low marginal costs, VREs tend to squeeze these flexible power plants out of the market, typically fossil-fuel power plants [51], and increase price risks [52]. This result does not mean that such a scenario is unrealistic. Nevertheless, this profitability issue should be anticipated by designing a suitable economic framework to remunerate backup power plants. The design of future markets and regulatory frameworks to better integrate VRE production is beyond the scope of this study.

The global decrease of availability factors in high RES power systems and the need for backup capacities (corresponding in our model to the peak load factor mentioned in the methodology section) capable of dealing with unexpected events induce the installation of high capacities (see Figure 10). 


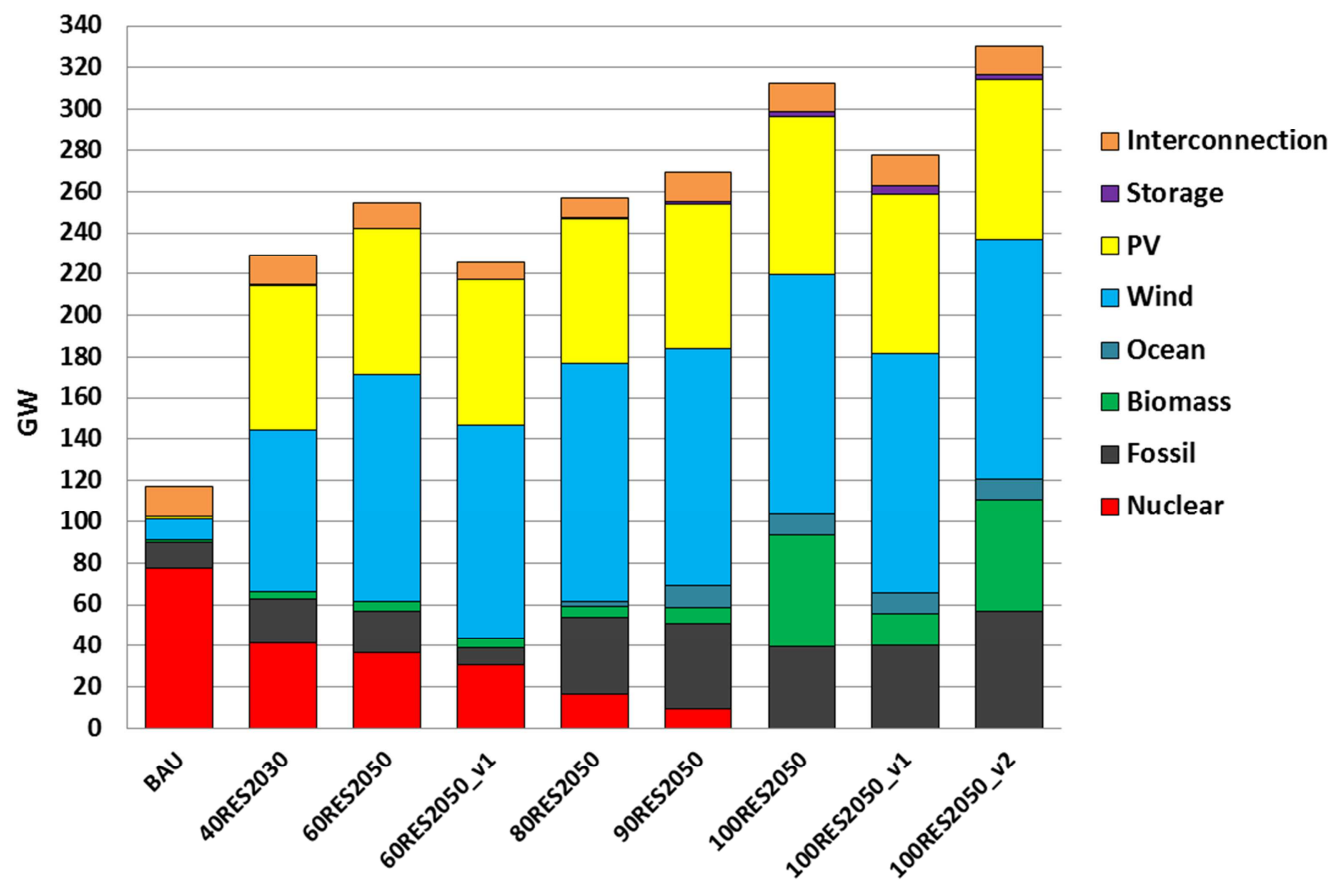

Figure 10. Overall installed capacity from 2013 to 2050 in the six reference scenarios and in three variants

Installed capacity more than doubles with the transition law objectives (40\% RES scenario) and more than triples in the $100 \%$ RES scenario compared to the $B A U$ scenario. The amount of fossil fuel power plants in the $80 \%$ and $100 \%$ RES scenarios (respectively 37 and $57 \mathrm{GW}$ compared to $12 \mathrm{GW}$ in a $B A U$ scenario) shows that these power plants are useful for balancing and back-up purposes even if their availability factor is low, as shown in Figure 9. Finally, in terms of installed capacity, the main differences between the $100 \%$ RES scenario and other scenarios with RES penetration objectives is the amount of installed capacity in fossil, biomass and ocean energy power plants that are not built for RES levels lower than $80 \%$, as well as new storage technologies installed only in the $90 \%$ and $100 \%$ RES scenarios. The levels of storage investments may seem quite low compared to those found in other studies (only $3 \mathrm{GW}$ in the reference 100\% RES scenario). For example, for the PJM interconnection in the Eastern part of the US ${ }^{19}$, one assessment verified the hourly dispatch during 4 years of demand and historical data of VRE production and found that between 0 and $10 \mathrm{GW}$ of storage capacities would be optimal for a $30 \%$ wind and solar share, and between 30 and $50 \mathrm{GW}$ for a $90 \%$ share, depending on cost assumptions [53, Fig. 5]. Other results point to an optimal storage capacity of $2.7 \mathrm{GW}$ of PHS and $12.5 \mathrm{GW}$ of grid-scale batteries for the UK in an $80 \%$ RES scenario, but with a higher share of PV in the installed VRE capacity [19, Sec. 4]. In our 80\% RES scenario, VREs (wind, solar and ocean energies) account for almost $60 \%$ of overall production, and only $5 \mathrm{GW}$ of existing storage (PHS) are installed. Nevertheless, these results should be compared with caution, since the power mixes are very different from one study to another. For instance, more than $24 \mathrm{GW}$ of exports are available every TS in 2050 in our study (see Table 2), which can play a similar role to perfect storage technology with $100 \%$ efficiency. Moreover, it is important to note that we did not simulate a period with high solar or wind production during a period of low or medium demand, which may increase the need for storage with more VREs in the power system.

\footnotetext{
${ }^{19}$ This area represents a power system around 1.7 times smaller than the one considered in the present study.
} 
Finally, it would seem that the temporal resolution of the model is of particular importance for assessing the potential role of storage as shown in [28], in which a 10-minute time-step model was used.

Accounting for new capacities and the power plants decommissioned during the period studied, installed capacity moves from $125 \mathrm{GW}$ currently to $115 \mathrm{GW}$ in 2050 in the $B A U$ scenario, $185 \mathrm{GW}$ in the $40 \%$ RES scenario, $224 \mathrm{GW}$ in the $90 \%$ RES scenario and $257 \mathrm{GW}$ in the $100 \%$ RES scenario. Note that in this last scenario about $32 \mathrm{GW}$ of fossil fuel capacities are no longer used in 2050, despite the fact that they have not reached the end of their lifetime. The huge amount of new capacities installed in the $100 \%$ RES scenario means an average of more than $8 \mathrm{GW}$ of new capacities each year (against less than $3 \mathrm{GW}$ in the $B A U$ scenario) with an annual peak of $12 \mathrm{GW}$ during the period 2045-2050. Therefore, such a scenario certainly requires a profound transformation of the power industry to design, build, operate and maintain so many power plants, most of which are not yet installed.

When there is no week with low wind and solar production (variant $v 1$ ), the installed capacity is reduced since there is no need for building additional power plants that aim at covering demand during this constrained week. In the case of the $60 \%$ RES scenario, the power plants that play this back-up role are fossil fuel-based power plants (see Figure 13): only $8 \mathrm{GW}$ are installed during the whole period in the variant $v 1$ compared to $20 \mathrm{GW}$ in the reference case. In the $100 \%$ RES scenario, this role is played by biomass power plants (see Figure 14): only $15 \mathrm{GW}$ are installed in the variant $v 1$ compared to $54 \mathrm{GW}$ in the reference case. On the contrary, in the variant where VREs do not participate in the peak load factor (variant $v 2$ ), there is a need for additional capacities, mainly fossil power plants, to meet the peak load factor described in the methodology section. The contribution of VREs to the peak load factor is an important assumption only in the $100 \%$ RES scenario as shown in the Figure 11.

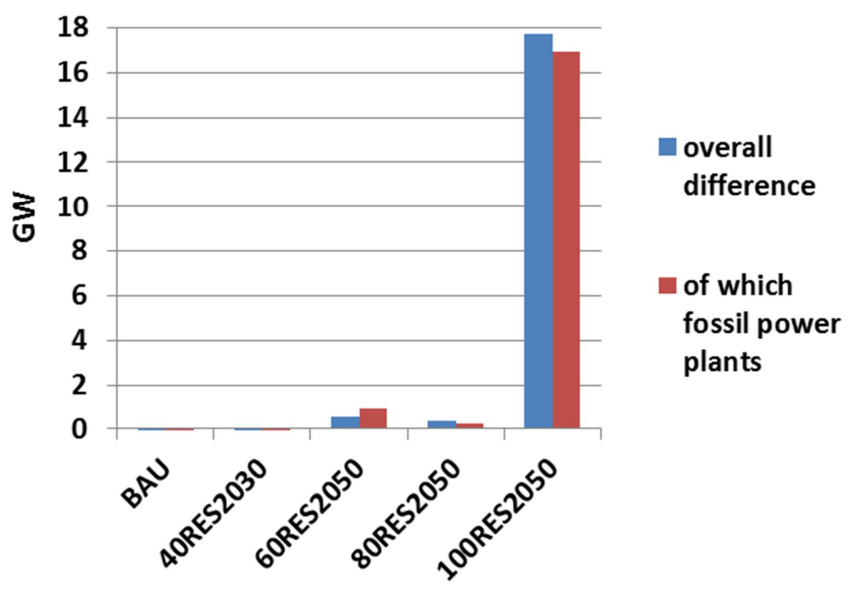

Figure 11. Difference in overall installed capacity (and fossil power plant capacity) with and without VREs contributing to the peak load factor in five scenarios

\subsection{The role of imports and biomass in high RES penetration scenarios}

RES penetration in power production will lead to a radical modification of power management, as illustrated in the figures below, which show power production throughout 2050 in three scenarios (BAU, 60\% RES and 100\% RES). In these figures, exports, storage capacity fulfillment, and postponed demand due to the use of demand-response technologies are counted negatively. On the contrary, power delivered by power plants and storage capacities as well as reduced demand, thanks to load-shedding, are counted positively. The 
following graphs represent the average power during each time-slice in GW to make comparable the time-slices of the model, which are of different durations ${ }^{20}$.

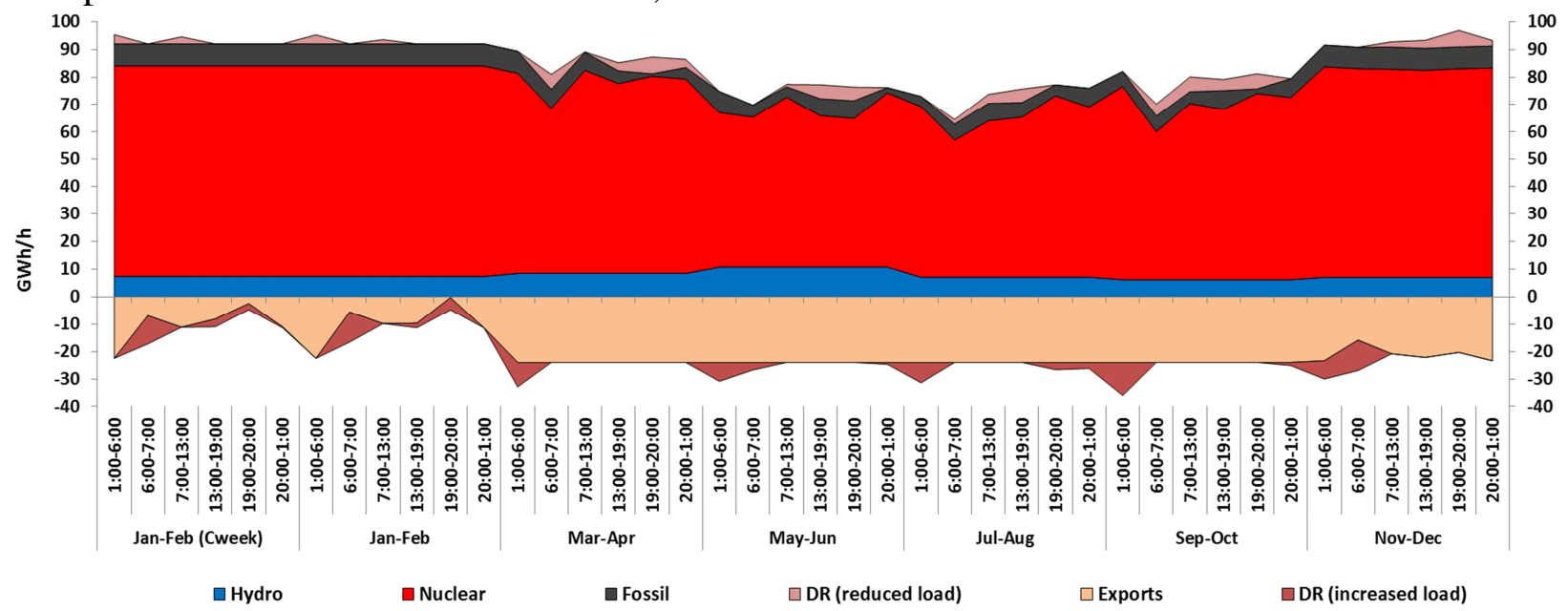

Figure 12. Power production in 2050 in the reference $B A U$ scenario

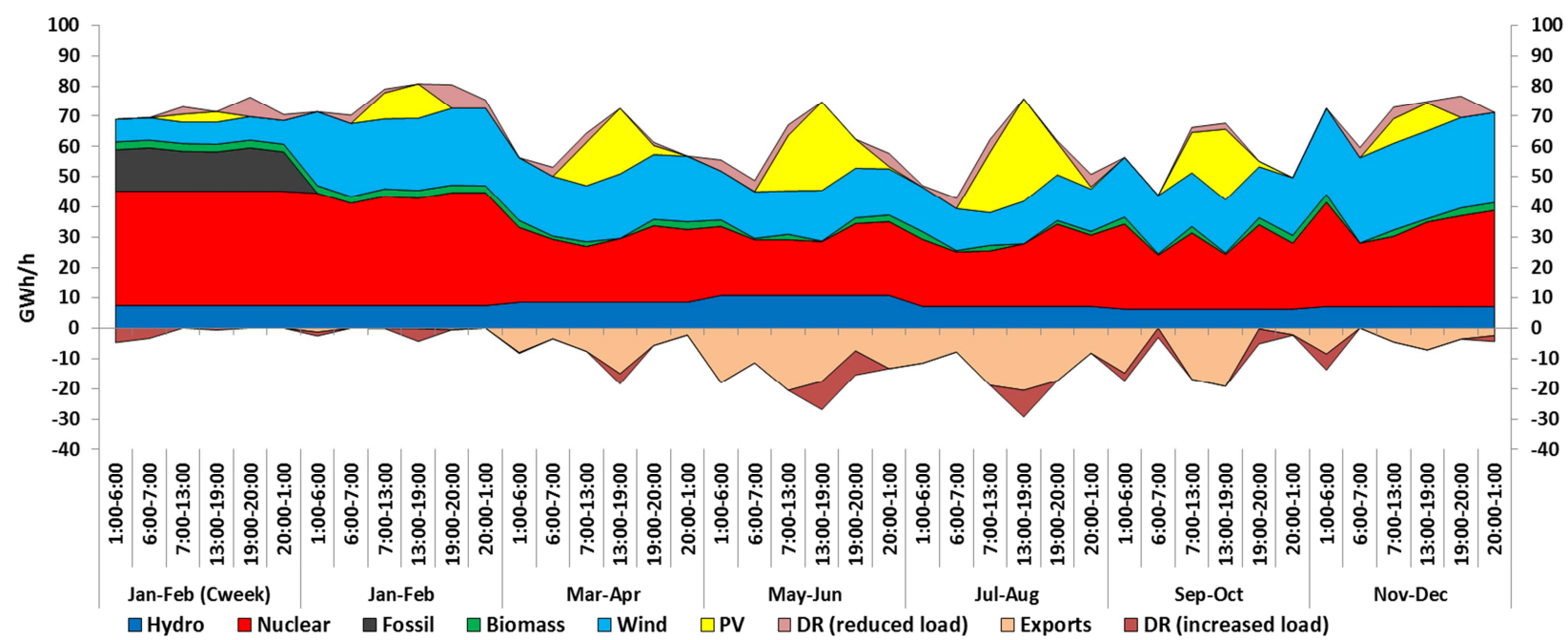

Figure 13. Power production in 2050 in the reference $60 \%$ RES scenario

\footnotetext{
${ }^{20}$ Especially the constrained week with low wind and PV production (CWeek), which represents only one week, compared to the other seasonal periods, which represent two months.
} 


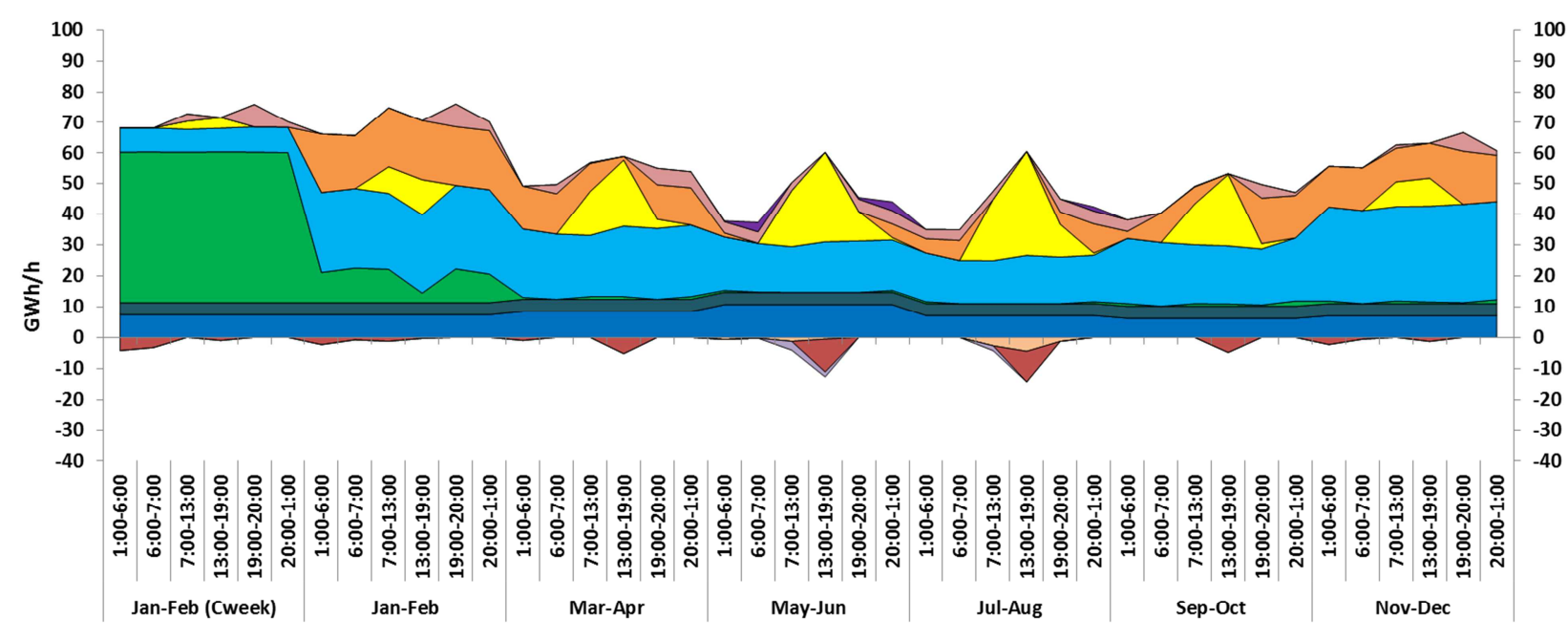

$\square$ Hydro $\square$ Ocean $\square$ Biomass $\square$ Wind $\square$ PV $\square$ Imports $\square$ DR (reduced load) $\square$ Storage (delivering) $\square$ Exports $\square$ DR (increased load) $\square$ Storage (loading)

Figure 14. Power production in 2050 in the reference $100 \%$ RES scenario

When power production is mainly based on nuclear power, in the $B A U$ scenario, the amount of electricity produced is almost constant through the year, with fewer exports during the winter when national demand is higher. Demand-response is used to move consumption from the day to night periods (especially from 1:00-6:00) when demand is lower. Exports are used to compensate the seasonal variability of demand, whereas demand-response is used for variability within the day. As RES penetration increases, wind and solar production gradually replace nuclear power. In the $60 \%$ RES scenario, a small amount of biomass production completes that of hydro for base load, fossil fuels are used only during the winter, especially when wind and PV production are low (Cweek time-slice), and power is now exported mainly during the day, when PV is producing. In the $100 \%$ RES scenario, ocean energy is added to hydro power as a base load production. Winter demand is now satisfied by biomass power plants, with almost all of the biomass potential being consumed during this season, especially when wind and PV production are low and imports impossible: during the Cweek time-slice, power from biomass power plants accounts for $70 \%$ of overall production. The huge amount of biomass capacity installed in this scenario (see Figure 10) is almost only used to cover demand during this week. This explains the very low use of biomass power plants in 2050 in this scenario as shown in Figure 9. Imports are used all year round to supplement national production, especially when PV production is low or inexistent; exports are now very low and only used when PV production is highest. Storage capacities are also employed during the summer season: loaded when PV production is high, they deliver power during the night. In the $60 \%$ and $100 \%$ RES scenarios, DR is used to move consumption from the night to the afternoon, when PV production is at its maximum, which is the opposite of the $B A U$ scenario. We see here the need to define DR strategies adapted to the power mix.

\subsection{The role of flexibility options in the $100 \%$ RES scenario}

Figure 14 shows the significance of imports and DR technologies in the 100\% RES scenario and Figure 8 shows the role of demand elasticity assumptions, which lead to reduced demand in high RES penetration scenarios. For the $100 \%$ RES variants, in which imports of electricity 
are not allowed in $2050^{21}$, or where neither demand elasticity nor DR technologies are available, it is not feasible to meet demand with the assumptions taken in this study (Figure 15 and Figure 17).

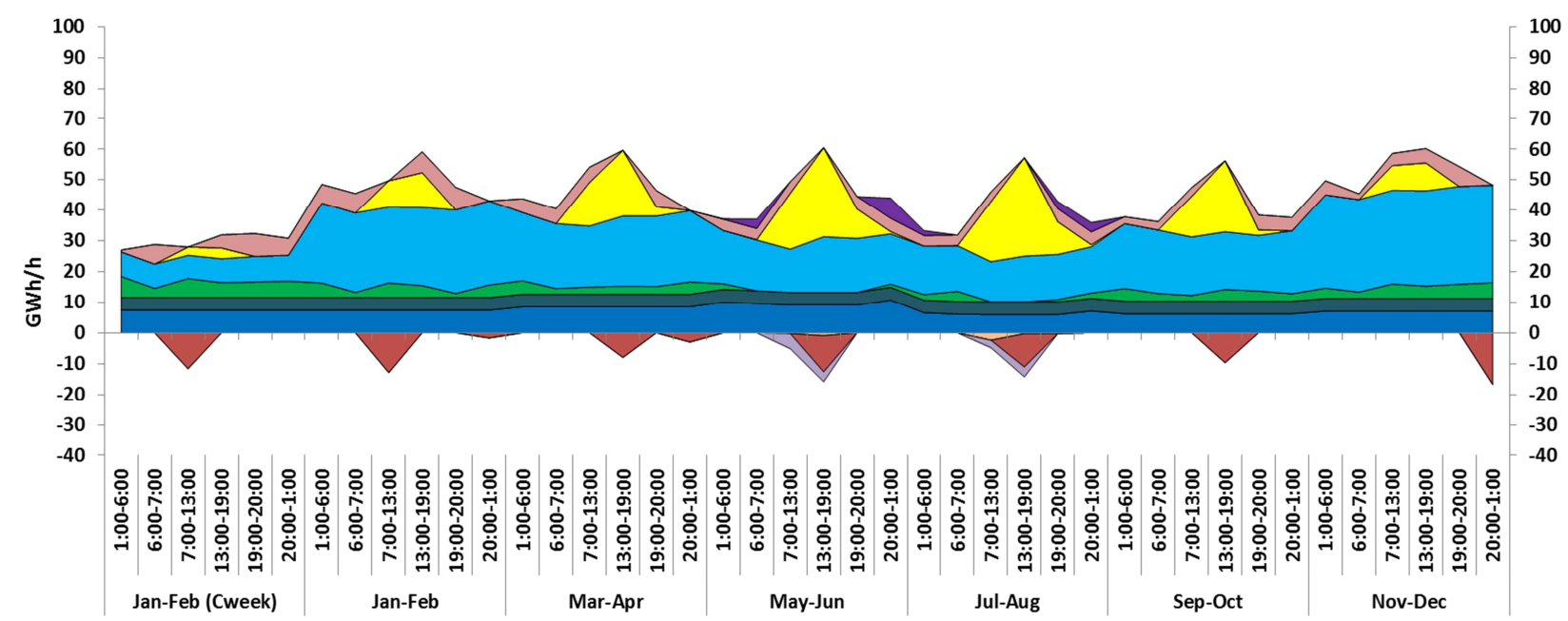

$\square$ Hydro $\square$ Ocean $\square$ Biomass $\square$ Wind $\square \mathrm{PV} \square$ Imports $\square \mathrm{DR}$ (reduced load) $\square$ Storage (delivering) $\square$ Exports $\square$ DR (increased load) $\square$ Storage (loading)

Figure 15. Power production in 2050 in the $100 \%$ RES scenario with no imports of electricity in 2050 (variant $v 3$ )

In variant $v 3$ of the $100 \%$ RES scenario, $57 \mathrm{TWh}$ of demand needs to be curtailed in 2050 for the supply-demand balance, mainly during the winter season, but also occasionally during other seasons. The distribution of the curtailment and demand elasticity is given in Figure 16:

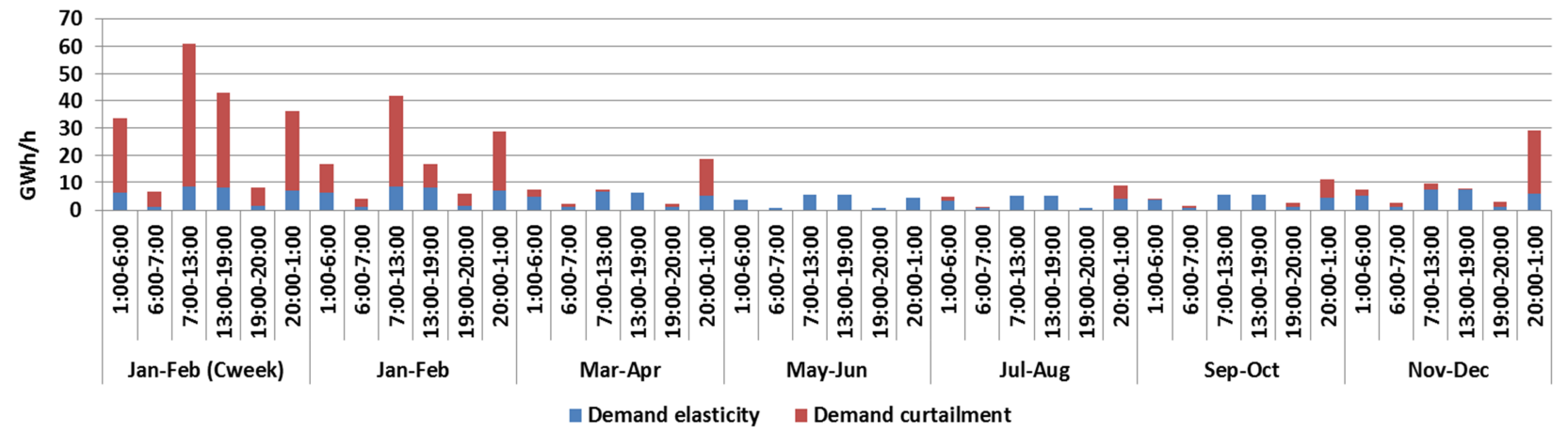

Figure 16. Demand curtailment and demand elasticity in 2050 in the $100 \%$ RES scenario with no imports of electricity in 2050 (variant v3)

Demand elasticity is used all year round to reduce overall demand and thus the power production required to meet this demand. On the contrary, demand curtailment is mostly used during the months of January and February when the power system is most constrained. Up to $60 \mathrm{GW}$ of demand have to be curtailed (by direct curtailment or because of the elasticity of demand) at some hours in this scenario.

\footnotetext{
${ }^{21}$ For instance, if neighboring countries also adopted a $100 \%$ RES penetration objective by 2050 , at times wind and solar production would be very low in the entire interconnected power system, despite the geographic smoothing of intermittent production fluctuations.
} 


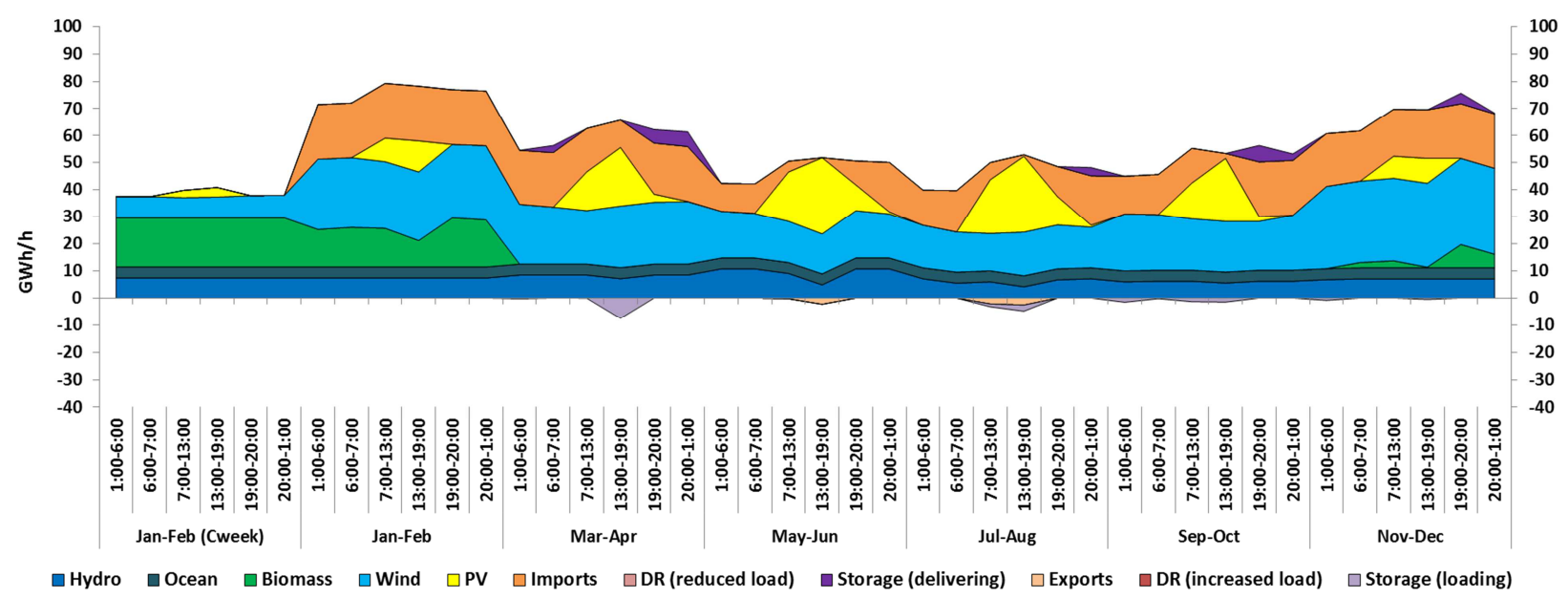

Figure 17. Power production in 2050 in the $100 \%$ RES scenario with no demand elasticity or DR technologies (variant $v 4$ )

In variant $v 4$ of the $100 \%$ RES scenario, $8 \mathrm{TWh}$ of demand needs to be curtailed in 2050 for supply-demand balance, only during the winter season, mostly when wind and solar productions are low.

In both variants (no imports and no flexibility on demand), the role of biomass has changed compared to the reference $100 \%$ RES scenario: biomass power plants are not only used in the week $C$ week featuring low wind and solar production, since they are needed to cover demand during other periods of the year.

Technologies that bring flexibility to the power system seem to be crucial for supply-demand balance in very high RES penetration scenarios. If they were not available, dispatchable power plants, for example based on biomass resources, could be required. Still, biomass resource limitations is a strong assumption in our model (1.3 Mtep of solid biomass and 1.3 Mtep from methanization in 2050 for power production purposes according to [49]). If this assumption is relaxed, in a $100 \%$ RES scenario the French power system could rely much more on biomass power plants and no longer depend on electricity imports (see Figure 18). In such a scenario, biomass and DR technologies absorb fluctuations of load and intermittent production.

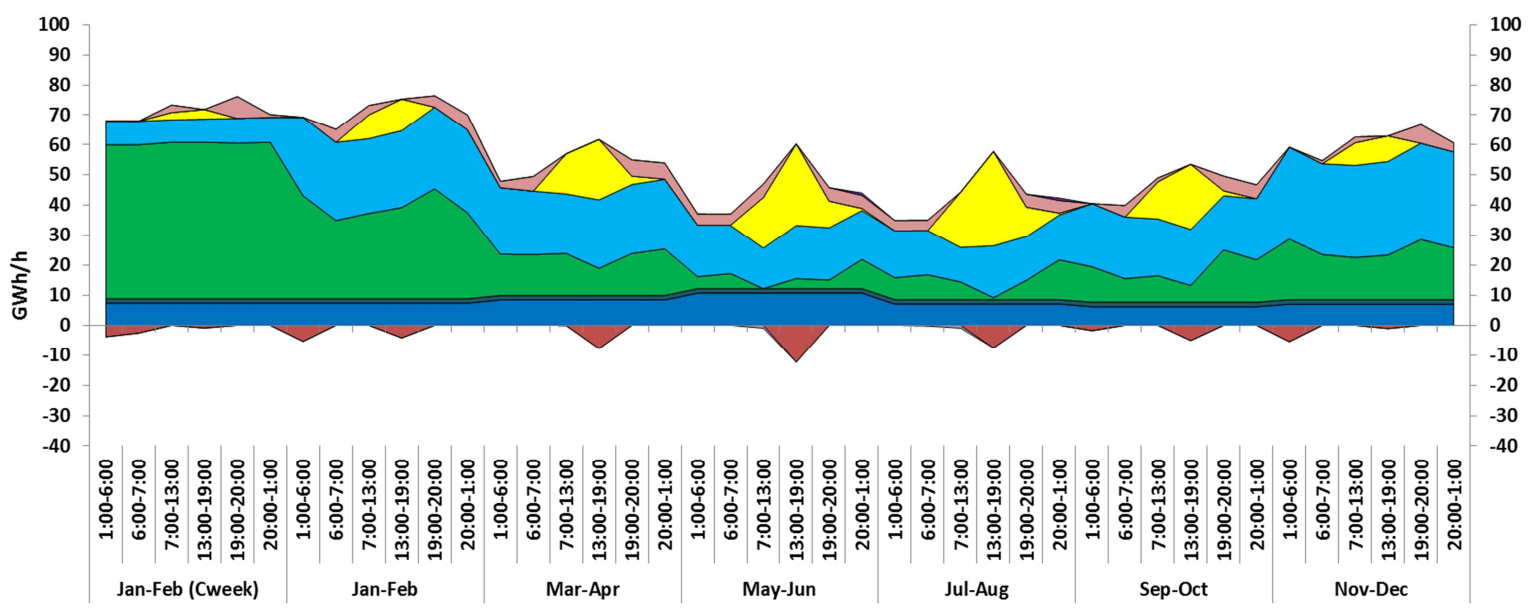

$\square$ Hydro $\square$ Ocean $\square$ Biomass $\square$ Wind $\square \mathrm{PV} \square$ Imports $\square$ DR (reduced load) $\square$ Storage (delivering) $\square$ Exports $\square$ DR (increased load) $\square$ Storage (loading)

Figure 18. Power production in 2050 in the $100 \%$ RES scenario with high biomass potential (variant $v 5$ ) 
Note that in this variant, no additional biomass power plants are installed compared to the reference 100\% RES scenario (see Figure 19): the same installed biomass capacity shows a much higher availability factor allowing much more electricity production.

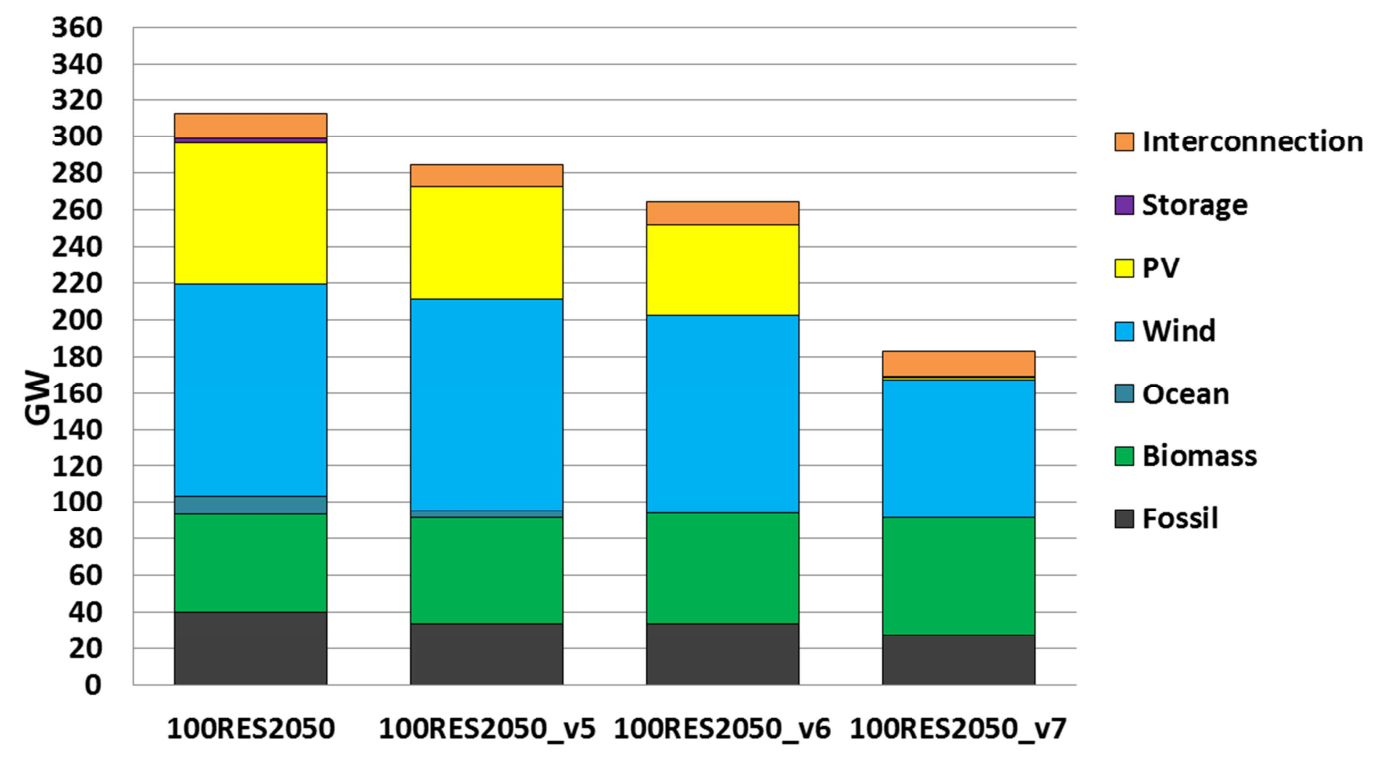

Figure 19. Overall installed capacity in the reference 100\% RES scenario and in three $100 \%$ RES variants with high biomass potential. The $6^{\text {th }}$ variant also includes a $50 \%$ limit on VRE penetration; in the $7^{\text {th }}$ variant this limit is $30 \%$

\subsection{RES penetration induces a decrease in kinetic and magnetic reserves that could make power system management more difficult}

The results presented above show that a supply-demand balance seems feasible in the different scenarios studied. Nevertheless, the long temporal period studied here makes it difficult to study balance on a short-term scale and for a wide range of demand and RES profile combinations. Therefore, the above analysis does not guarantee that demand may be satisfied in every circumstance. Moreover, an imbalance between supply and demand could cause a black-out in the power system. To complete our prospective analysis, we also study the evolution of power system kinetic and magnetic reserves with RES penetration: it was demonstrated in [31] that low levels of these reserves could compromise power system management.

Figure 20 shows how kinetic reserves decrease as RES penetration increases. Magnetic reserves are not represented in this study but they evolve with a similar trend. This decrease is correlated to the proportion of power produced by VRE power plants since they do not contribute to these reserves as explained above in the methodology section. 


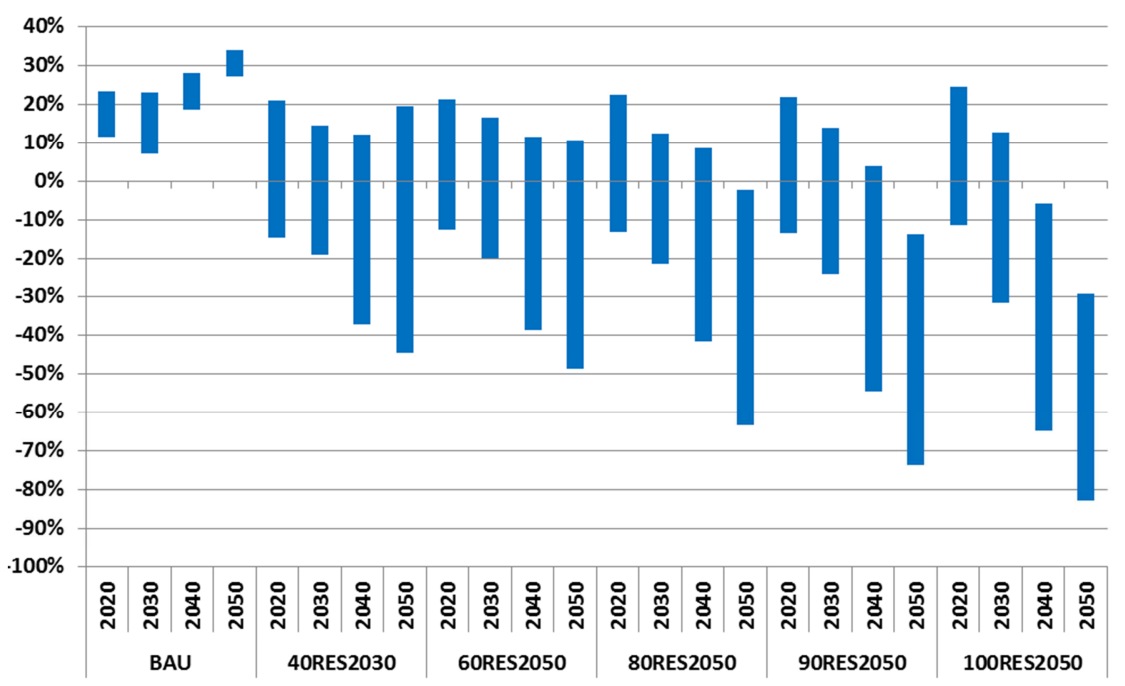

Figure 20. Evolution of the deviation of kinetic reserves from 2020 to 2050 in the reference scenarios compared to the minimum value observed in 2012. The top and the bottom of the bars respectively indicate the maximum and minimum value for kinetic reserves observed during one year

In a $B A U$ scenario, kinetic reserves should remain higher than the minimum level of 2012, so we could consider that such a scenario would lead to a sufficiently reliable power system. In 2050 , beyond $40 \%$ of RES penetration, there should be periods of the year during which kinetic reserves would be $40 \%$ lower than the minimum level observed in 2012 . In the $100 \%$ RES scenario, these reserves should always be lower than the minimum level observed in 2012, sometimes reaching $80 \%$ lower.

In Figure 20, imports make no contribution to kinetic reserves. Indeed, we have not studied the power mix evolution in neighboring countries and thus have no information as to how power plants could participate in power production in these countries in the long term. Therefore, we test a cautious hypothesis in which imports do not participate in kinetic and magnetic reserves, along with an intermediate hypothesis in which half of the imported power would participate in these reserves. Moreover, in Figure 20, wind power plants make no contribution to kinetic reserves either. This is also a cautious hypothesis since their contribution to these reserves is not clear yet. Nevertheless, we also test a counterfactual $100 \%$ RES penetration scenario, with wind power plants contributing to kinetic reserves based on an inertial momentum value from [54]. These assumptions are compared in Figure 21 for the $100 \%$ RES scenario. 


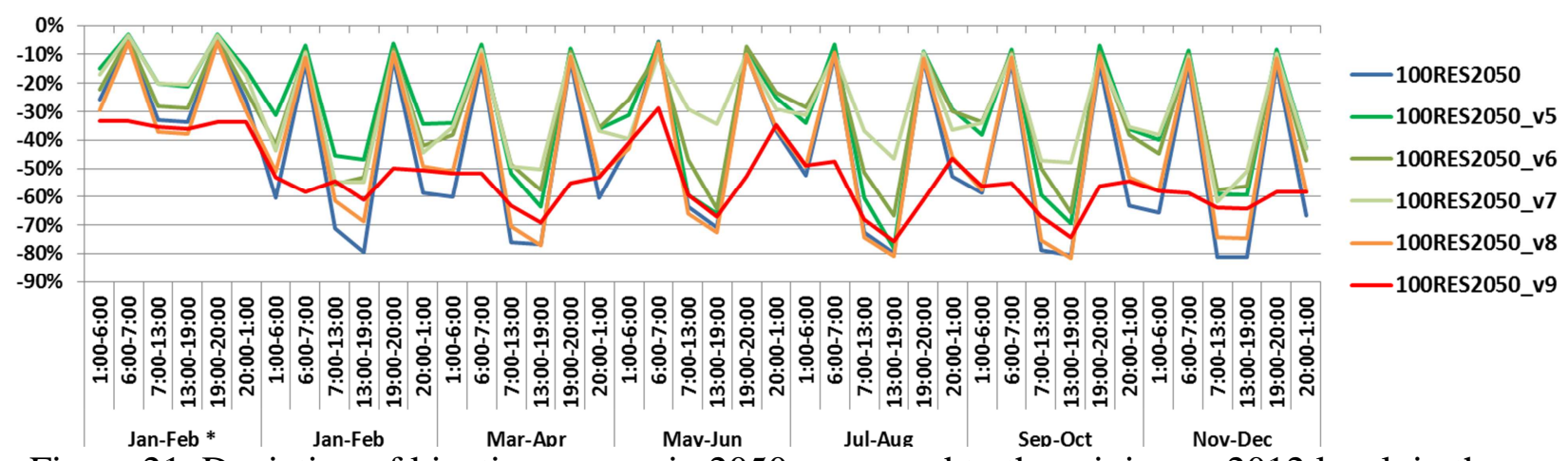

Figure 21. Deviation of kinetic reserves in 2050 compared to the minimum 2012 level, in the reference $100 \%$ RES scenario, with import contribution (variant $v 8$ ) / wind contribution (variant $v 9$ ), and in three variants with high biomass potential (variants $v 5-v 7$ )

Because of the high amount of imports and wind production in this scenario, we can see that if imports or wind did contribute to kinetic reserves (variants $v 8$ and $v 9$ ), they would somewhat increase these reserves, although not enough to reach 2012 kinetic reserve levels. In the case involving wind contribution to kinetic reserves (variant $v 9$ ), this is because wind turbines' inertial constants are low compared to those of conventional power plants (about $0.6 \mathrm{~s}$ compared to $2-7 \mathrm{~s}$ ). Kinetic reserves were also plotted for variants $v 5$ to $v 7$ (see Table 7 ). In all of these variants, a high biomass potential was considered, and in $v 6$ and $v 7$ a limitation on VREs penetration was added (respectively 50\% and 30\%). Since biomass power plants do contribute to kinetic reserves, they help reduce their deterioration in $100 \%$ RES penetration scenarios. Nevertheless, during some periods, typically summer afternoons, kinetic reserves in variant $v 5$ are still as low as they are in the reference $100 \%$ RES scenario ${ }^{22}$. By putting some limitations on VRE penetration, kinetic reserves can be maintained to a higher level all year round (although remaining low during some periods), especially during the summer season, since the amount of PV production has been strongly reduced in variant $v 6$ and suppressed in variant $v 7$ (see Figure 22).

Note that in the period when solar PV and wind do not contribute significantly to power supply (Cweek time-slice), which is then provided by biomass (see Figure 14, Figure 18 and Figure 22), kinetic reserves are higher than they are in all other seasonal periods.

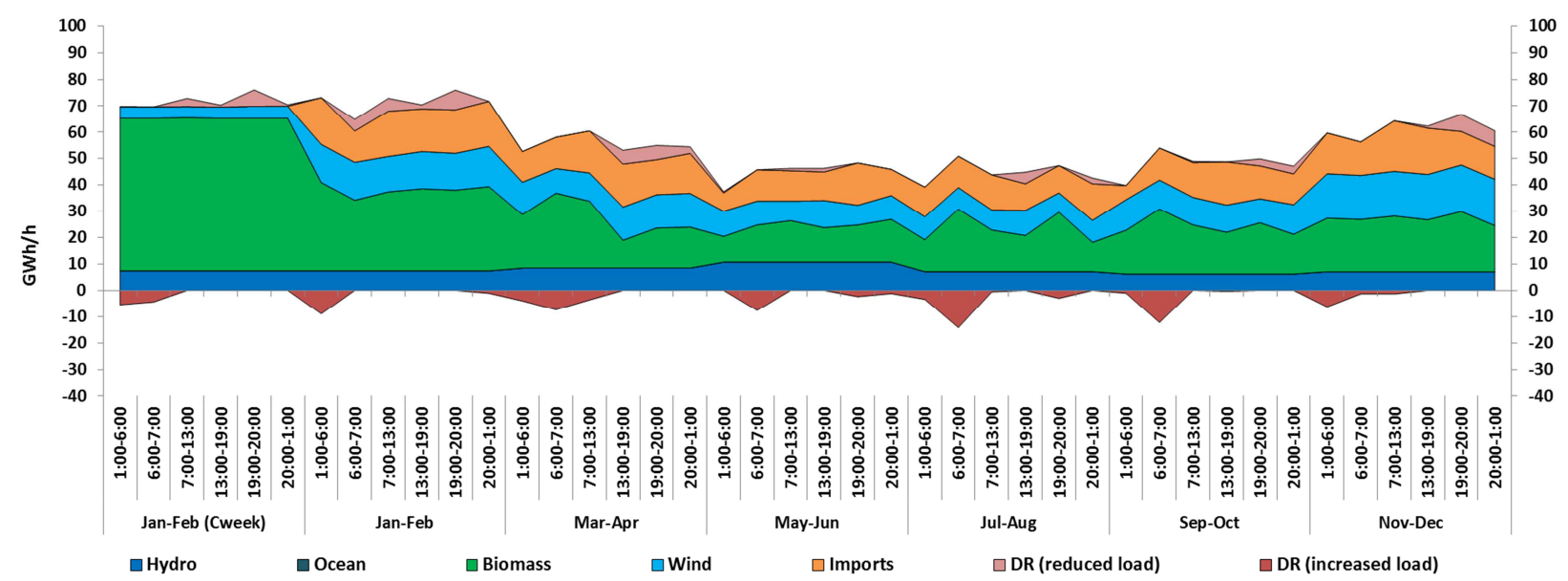

Figure 22. Power production in 2050 in the $100 \%$ RES scenario with high biomass potential and a limitation of $30 \%$ VRE penetration (variant $v 7$ )

\footnotetext{
${ }^{22}$ Down to $80 \%$ less than the minimum value of the current French power system.
} 


\subsection{RES penetration results in higher power systems costs, and especially higher investment costs}

RES penetration requires huge amounts of installed capacity (see Figure 10). Thus, we expect higher investment costs as the RES share in the power mix increases. Figure 23 shows a contrasted evolution of annual costs with RES penetration: investment costs tend to increase but not gradually, for example they are lower in the $80 \%$ RES scenario than in the $60 \%$ RES scenario. This is because much more nuclear is installed in the $60 \%$ RES scenario (37 GW) than in the $80 \%$ RES scenario $(17 \mathrm{GW})$ and nuclear power plants require significant investment costs but allow high exports due to their high availability factor (in the $60 \%$ RES scenario $770 \mathrm{TWh}$ are exported between 2020 and 2050, compared to $385 \mathrm{TWh}$ in the $80 \%$ RES scenario). The export revenue can be used to pay back the high investments in nuclear capacities with the assumptions made in this study. Operation and maintenance costs tend to be higher with more RES, whereas costs related to the activity of power plants could go down slightly. The reduction of demand related to higher electricity prices also causes costs to rise with RES penetration. Lower fuel costs result from a reduction in the use of fossil fuels as the share of RES in the power mix increases. Import costs minus export revenue rises strongly with RES penetration because of the sharp export decrease and, when RES penetration is very high (from 80\%), imports increase. The power trade-balance is inverted (see Figure 6). Finally, the overall discounted cost is about $11 \%$ higher in the $40 \%$ RES scenario compared to the BAU scenario, 20\% higher in the $90 \%$ RES scenario, and $30 \%$ in the $100 \%$ RES scenario. The latter percentages of RES integration in the French power system seem to be the most expensive. This is mainly due to the need for massive biomass installation during the last decade as well as the high amount of imported power and the reduction of exports, which result in lower revenues.

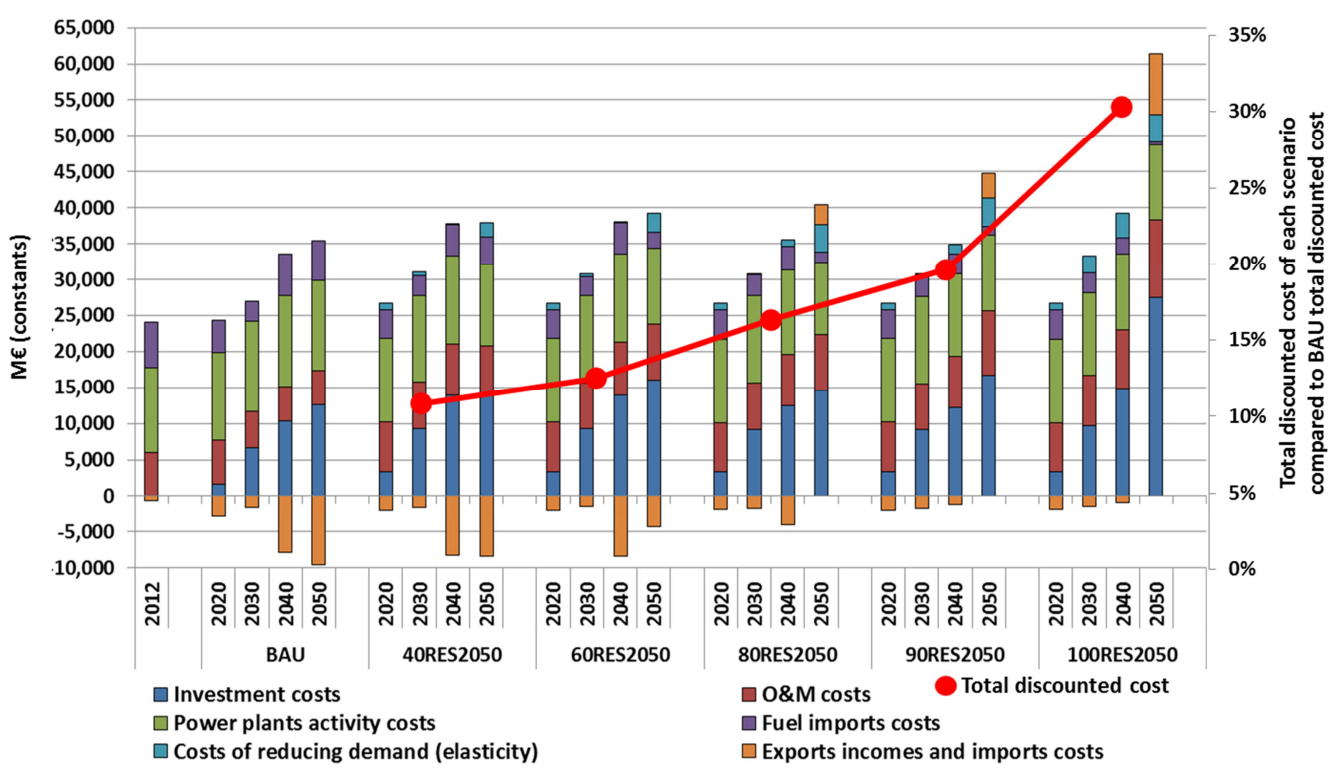

Figure 23. Evolution of annual costs in the reference scenarios and total discounted cost of each scenario compared with the total discounted cost of the $B A U$ scenario

The annual costs and total discounted cost of the 100\% RES variants are given in Figure 24. 


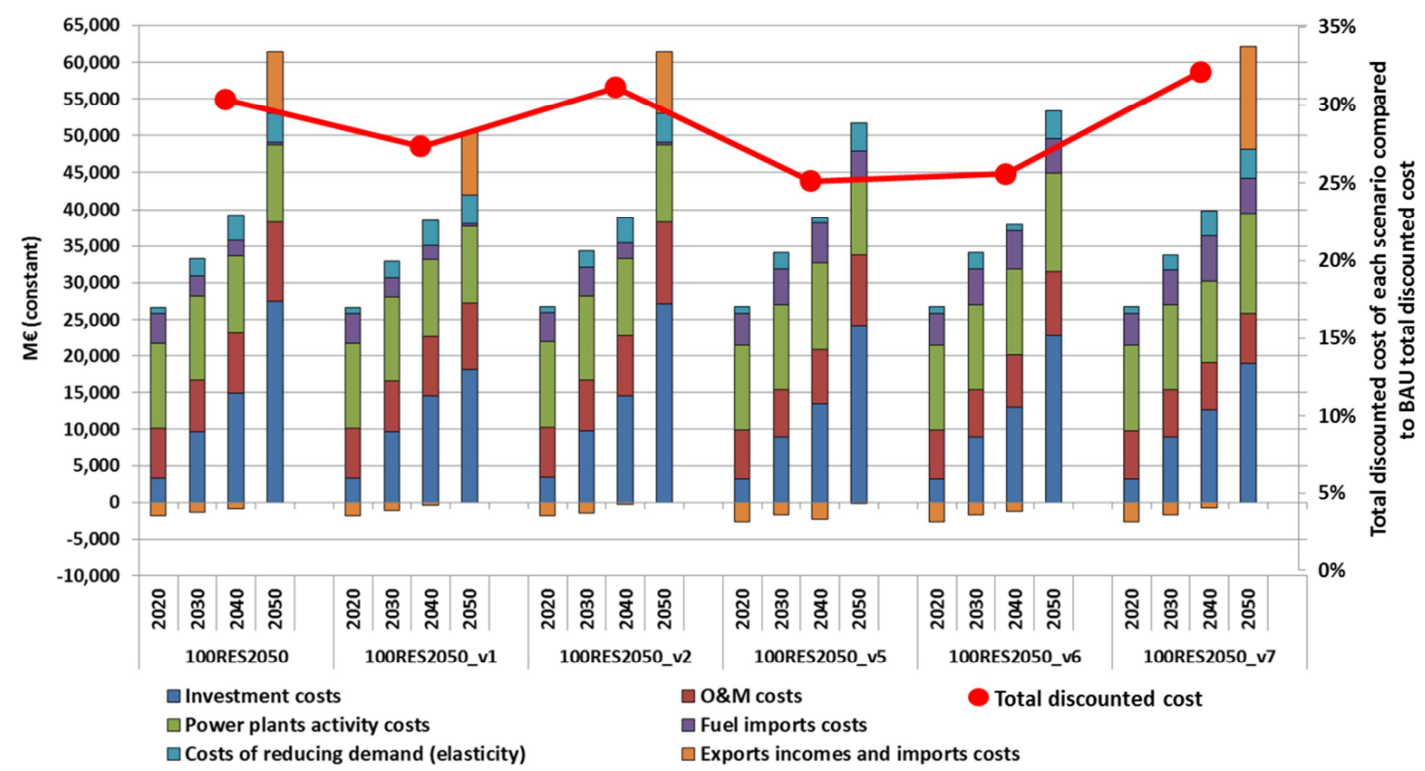

Figure 24. Evolution of annual costs in the $100 \%$ RES variants and total discounted cost of each scenario compared with the total discounted cost of the $B A U$ scenario

Note that the costs of variants $v 3$ and $v 4$ are not given on this figure because in these variants demand has to be curtailed for supply-demand purposes (see Figure 17Figure 18), which is extremely costly in the model (this possibility is used as a last resort after every other option). It would thus not be convenient to show all the costs on the same figure, since the cost of curtailment is several orders of magnitude higher than the other costs.

Costs in variants $v 1$ and $v 2$ follow installed capacity (see Figure 10). Investment and operation and maintenance costs are lower in 2050 in $v 1$ and slightly higher in 2030 in v2 compared to the reference $100 \%$ RES scenario. Relaxing assumptions on biomass potential (variant v5) leads to reduced investment costs and import costs, but the higher use of biomass resources brings higher fuel costs. A strong constraint on VRE penetration, as in variant $v 7$ (maximum $30 \%$ VRE penetration) requires very high levels of imports and, even if investment costs are reduced, the overall cost is the same as in the reference $100 \%$ RES scenario.

\subsection{Summary of the main results}

In the present study, RES penetration in the French power system has been analyzed from both an economic and a technical point of view. The main results of this work can be summed up as follows:

- The RES potential assessed by the French National Agency on Environment and Energy Management (ADEME) in [49] (Table 2) does not seem sufficient to meet the future demand considered in this study (Table 4) without the help of conventional power plants or strongly resorting to imports, whose availability has not been assessed in this study and which depend on the evolution of the whole European power system. When RES penetration reaches $100 \%$ and no imports are available in 2050 (variant $v 3$ of the scenario 100\% RES 2050), significant demand has to be curtailed (Figure 16). Moreover, energy efficiency and demand response are both important to reach high RES penetration levels; this is because some demand curtailment also occurs without demand elasticity and available demand response (variant $v 4$ of the scenario 100\% RES 2050).

- In the assumptions made in this study, it seems that the optimal share of VREs in the main $100 \%$ RES 2050 scenario is $65 \%$ with about five-eighths of VRE production from wind, 
two-eighths from solar PV, and one-eighth from ocean energies (Table 10). Note that ocean energy is used only when a very high VRE share is considered (more than 90\%). Storage seems to play only a minor role in our scenarios but, compared to other similar studies, we have considered demand-response technologies, which are free here, and help integrate hourly fluctuations of residual demand (Figure 12Figure 14). Moreover, the possibility to import electricity at any time of the year acts as perfect storage without any loss, and is combined with quite a high level of interconnections with neighboring countries (up to $20 \mathrm{GW}$ in 2050).

- The penetration of RES technologies in the French power system could lead to additional costs, from $11 \%$ to $32 \%$ more than in the $B A U$ scenario depending on the RES penetration level and the assumptions made (Table 9) ${ }^{23}$. These additional costs are mainly due to the massive installation of new power plants because of the low availability of VREs, but also the need for back-up capacities (Figure 10 and Figure 19), leading to high investment costs but also high operation and maintenance costs (Figure 23 and Figure 24). The activity costs are slightly reduced and the fuel costs strongly reduced, but because the latter are not the main component of the overall cost in the case of the French power system, this effect is only slight. Finally, the inversion of the power-trade balance between $60 \%$ and $80 \%$ of RES penetration is also responsible for lower revenues and higher costs, and the reduction in demand due to demand elasticity is another source of supplementary costs (Figure 23 and Figure 24).

- Finally, VRE penetration in the power system leads to a significant reduction of kinetic reserves, down to $65 \%$ less on average in the reference $100 \%$ RES 2050 scenario compared to the minimum value observed in 2012 and with a higher variance than in the $B A U$ scenario (Table 10). The study of the impacts caused by these low kinetic reserves is beyond the scope of our work. Nevertheless, one should keep in mind that these reserves are crucial for power system stability and that such a strong reduction could cause serious problems in terms of power system regulation.

\footnotetext{
${ }^{23}$ The cost of variants $v 3$ and $v 4$ has not been reported since these variants require demand curtailment, the cost of which is several orders of magnitude higher than other costs.
} 
Table 9: Installed capacities, power trade balance, load reduction and use of storage in 2050, primary resource consumption during the whole period (2012-2050), and overall leveled cost compared to that of the BAU scenario, for some of the studied scenarios

\begin{tabular}{|c|c|c|c|c|c|c|c|c|c|}
\hline 2050 & BAU & $\begin{array}{c}\text { 40RES } \\
2030\end{array}$ & $\begin{array}{c}\text { 60RES } \\
2050\end{array}$ & $\begin{array}{c}\text { 80RES } \\
2050\end{array}$ & $\begin{array}{c}\text { 90RES } \\
2050\end{array}$ & $\begin{array}{c}\text { 100RES } \\
2050\end{array}$ & $\begin{array}{l}\text { 100RES } \\
\text { 2050_v1 }\end{array}$ & $\begin{array}{l}\text { 100RES } \\
\text { 2050_v5 }\end{array}$ & $\begin{array}{l}\text { 100RES } \\
\text { 2050_v7 }\end{array}$ \\
\hline $\begin{array}{l}\text { Nuclear } \\
\text { (GW) }\end{array}$ & $\begin{array}{r}80.7 \\
(+78)\end{array}$ & $\begin{array}{r}44.2 \\
(+41)\end{array}$ & $\begin{array}{r}39.8 \\
(+37)\end{array}$ & $\begin{array}{r}19.5 \\
(+17)\end{array}$ & $\begin{array}{r}9.3 \\
(+9.3)\end{array}$ & $\begin{array}{r}0.0 \\
(+0.0)\end{array}$ & $\begin{array}{r}0.0 \\
(+0.0)\end{array}$ & $\begin{array}{r}0.0 \\
(+0.0)\end{array}$ & $\begin{array}{r}0.0 \\
(+0.0)\end{array}$ \\
\hline $\begin{array}{l}\text { Fossil } \\
\text { (GW) }\end{array}$ & $\begin{array}{r}7.9 \\
(+12)\end{array}$ & $\begin{array}{r}16.2 \\
(+22)\end{array}$ & $\begin{array}{r}15.9 \\
(+20)\end{array}$ & $\begin{array}{r}33.5 \\
(+38)\end{array}$ & $\begin{array}{r}37.4 \\
(+42)\end{array}$ & $\begin{array}{r}31.9 \\
(+40)\end{array}$ & $\begin{array}{r}32.5 \\
(+40)\end{array}$ & $\begin{array}{r}26.8 \\
(+33)\end{array}$ & $\begin{array}{r}21.5 \\
(+28)\end{array}$ \\
\hline $\begin{array}{l}\text { Hydro } \\
\text { (GW) }\end{array}$ & $\begin{array}{r}21.7 \\
(+0.9)\end{array}$ & $\begin{array}{r}21.7 \\
(+0.9)\end{array}$ & $\begin{array}{r}21.7 \\
(+0.9)\end{array}$ & $\begin{array}{r}21.7 \\
(+0.9)\end{array}$ & $\begin{array}{r}21.7 \\
(+0.9)\end{array}$ & $\begin{array}{r}21.7 \\
(+0.9)\end{array}$ & $\begin{array}{r}21.7 \\
(+0.9)\end{array}$ & $\begin{array}{r}21.7 \\
(+0.9)\end{array}$ & $\begin{array}{r}21.7 \\
(+0.9)\end{array}$ \\
\hline $\begin{array}{l}\text { Biomass } \\
\text { (GW) }\end{array}$ & $\begin{array}{r}0.0 \\
(+1.5)\end{array}$ & $\begin{array}{r}1.1 \\
(+3.5)\end{array}$ & $\begin{array}{r}2.5 \\
(+4.9)\end{array}$ & $\begin{array}{r}2.9 \\
(+5.2)\end{array}$ & $\begin{array}{r}5.5 \\
(+7.8)\end{array}$ & $\begin{array}{r}51.5 \\
(+54)\end{array}$ & $\begin{array}{r}12.9 \\
(+15)\end{array}$ & $\begin{array}{r}54.3 \\
(+58)\end{array}$ & $\begin{array}{r}60.4 \\
(+64)\end{array}$ \\
\hline $\begin{array}{l}\begin{array}{l}\text { Ocean } \\
(\mathbf{G W})\end{array} \\
\end{array}$ & $\begin{array}{r}0.0 \\
(+0.0)\end{array}$ & $\begin{array}{r}0.0 \\
(+0.0)\end{array}$ & $\begin{array}{r}0.0 \\
(+0.0)\end{array}$ & $\begin{array}{r}2.1 \\
(+2.1)\end{array}$ & $\begin{array}{r}10.1 \\
(+10)\end{array}$ & $\begin{array}{r}10.0 \\
(+10)\end{array}$ & $\begin{array}{r}10.0 \\
(+10)\end{array}$ & $\begin{array}{r}3.7 \\
(+3.7)\end{array}$ & $\begin{array}{r}0.0 \\
(+0.0)\end{array}$ \\
\hline $\begin{array}{l}\text { Wind } \\
\text { (GW) }\end{array}$ & $\begin{array}{r}0.0 \\
(+9.7)\end{array}$ & $\begin{array}{r}31.9 \\
(+78)\end{array}$ & $\begin{array}{r}64.0 \\
(+110)\end{array}$ & $\begin{array}{r}70.0 \\
(+115)\end{array}$ & $\begin{array}{r}70.0 \\
(+115)\end{array}$ & $\begin{array}{r}70.0 \\
++116)\end{array}$ & $\begin{array}{r}70.0 \\
(+116)\end{array}$ & $\begin{array}{r}70.0 \\
(+116)\end{array}$ & $\begin{array}{r}29.4 \\
(+75)\end{array}$ \\
\hline $\begin{array}{l}\text { PV } \\
\text { (GW) }\end{array}$ & $\begin{array}{r}0.0 \\
(+1.4)\end{array}$ & $\begin{array}{r}65.0 \\
(+70)\end{array}$ & $\begin{array}{r}65.0 \\
(+70)\end{array}$ & $\begin{array}{r}65.0 \\
(+70)\end{array}$ & $\begin{array}{r}65.0 \\
(+70)\end{array}$ & $\begin{array}{r}65.0 \\
(+77)\end{array}$ & $\begin{array}{r}65.0 \\
(+77)\end{array}$ & $\begin{array}{r}60.0 \\
(+61)\end{array}$ & $\begin{array}{r}0.0 \\
(+1.4)\end{array}$ \\
\hline $\begin{array}{l}\text { Storage } \\
\text { (GW) }\end{array}$ & $\begin{array}{r}4.6 \\
(+0.2)\end{array}$ & $\begin{array}{r}4.5 \\
(+0.1)\end{array}$ & $\begin{array}{r}4.4 \\
(+0.0)\end{array}$ & $\begin{array}{r}4.8 \\
(+0.4)\end{array}$ & $\begin{array}{r}5.0 \\
(+0.6)\end{array}$ & $\begin{array}{r}7.2 \\
(+2.8)\end{array}$ & $\begin{array}{r}8.9 \\
(+4.6)\end{array}$ & $\begin{array}{r}4.4 \\
(+0.0)\end{array}$ & $\begin{array}{r}5.1 \\
(+0.8)\end{array}$ \\
\hline $\begin{array}{l}R E S \\
(G W) \\
\end{array}$ & $\begin{array}{r}21.7 \\
(+13)\end{array}$ & $\begin{array}{r}119.7 \\
(+152)\end{array}$ & $\begin{array}{r}153.3 \\
(+185)\end{array}$ & $\begin{array}{r}161.6 \\
(+193)\end{array}$ & $\begin{array}{r}172.3 \\
(+203)\end{array}$ & $\begin{array}{r}218.1 \\
(+257)\end{array}$ & $\begin{array}{r}179.6 \\
(+218)\end{array}$ & $\begin{array}{r}209.7 \\
(+239)\end{array}$ & $\begin{array}{r}111.6 \\
(+141)\end{array}$ \\
\hline $\begin{array}{l}\text { Total } \\
\text { (GW) }\end{array}$ & $\begin{array}{r}114.9 \\
(+117)\end{array}$ & $\begin{array}{r}184.6 \\
(+229)\end{array}$ & $\begin{array}{r}213.3 \\
(+255)\end{array}$ & $\begin{array}{r}219.4 \\
(+257)\end{array}$ & $\begin{array}{r}223.9 \\
(+269)\end{array}$ & $\begin{array}{r}257.2 \\
(+313)\end{array}$ & $\begin{array}{r}221.1 \\
(+278)\end{array}$ & $\begin{array}{r}240.9 \\
(+285)\end{array}$ & $\begin{array}{r}138.2 \\
(+183)\end{array}$ \\
\hline $\begin{array}{l}\text { Imports } \\
\text { (GW) }\end{array}$ & $\begin{array}{r}24.0 \\
(+15)\end{array}$ & $\begin{array}{r}24.0 \\
(+15)\end{array}$ & $\begin{array}{r}22.0 \\
(+13)\end{array}$ & $\begin{array}{r}19.1 \\
(+10)\end{array}$ & $\begin{array}{r}24.0 \\
(+15)\end{array}$ & $\begin{array}{r}23.0 \\
(+14)\end{array}$ & $\begin{array}{r}24.0 \\
(+15)\end{array}$ & $\begin{array}{r}22.0 \\
(+13)\end{array}$ & $\begin{array}{r}23.0 \\
(+14)\end{array}$ \\
\hline $\begin{array}{l}\begin{array}{l}\text { Trade } \\
\text { balance } \\
\text { (TWh) }\end{array} \\
\end{array}$ & 191 & 167 & 86 & -15 & -24 & -68 & -68 & 2 & -116 \\
\hline $\begin{array}{l}\text { Load } \\
\text { reduction } \\
\text { (TWh) }\end{array}$ & 0.0 & 30.6 & 40.0 & 53.6 & 53.6 & 53.6 & 53.6 & 53.6 & 53.6 \\
\hline $\begin{array}{l}\text { Storage } \\
(T W h)\end{array}$ & 0.7 & 0.4 & 0.0 & 3.6 & 3.8 & 2.9 & 3.0 & 0.5 & 0.9 \\
\hline $\begin{array}{l}\text { Fossil } \\
\text { resources } \\
\text { (Mtep) }\end{array}$ & 144 & 119 & 102 & 87 & 87 & 118 & 117 & 119 & 104 \\
\hline $\begin{array}{l}\text { Biomass } \\
\text { resources. } \\
\text { (Mtep) }\end{array}$ & 32 & 43 & 43 & 44 & 47 & 48 & 48 & 105 & 130 \\
\hline $\begin{array}{l}\text { Overall } \\
\text { cost / BAU }\end{array}$ & NA & $11 \%$ & $13 \%$ & $16 \%$ & $20 \%$ & $30 \%$ & $27 \%$ & $25 \%$ & $32 \%$ \\
\hline
\end{tabular}

NA: Not Applicable

All figures are given for the year 2050 except fossil and biomass resource consumption and the overall costs, which are calculated for the whole period (2012-2050). The installed capacities are given for 2050 and the overall new capacities installed during the whole period are given in the form $(+X X)$. 
Table 10: VRE share in power production in 2050 and relative kinetic reserves (minimum, average and maximum) in 2050 compared to the minimum value observed in 2012 for some of the studied scenarios

\begin{tabular}{|c|c|c|c|c|c|c|c|c|c|}
\hline 2050 & BAU & $\begin{array}{l}\text { 40RES } \\
2030\end{array}$ & $\begin{array}{l}\text { 60RES } \\
2050\end{array}$ & $\begin{array}{l}\text { 80RES } \\
2050\end{array}$ & $\begin{array}{l}\text { 90RES } \\
2050\end{array}$ & $\begin{array}{l}\text { 100RES } \\
2050\end{array}$ & $\begin{array}{l}\text { 100RES } \\
2050 \_v 1\end{array}$ & $\begin{array}{l}\text { 100RES } \\
2050 \_v 5\end{array}$ & $\begin{array}{l}\text { 100RES } \\
2050 \_v 7\end{array}$ \\
\hline$\%$ VREs & $0 \%$ & $29 \%$ & $45 \%$ & $57 \%$ & $64 \%$ & $65 \%$ & $65 \%$ & $59 \%$ & $22 \%$ \\
\hline $\begin{array}{l}\text { \%Ocean / } \\
\text { VRE }\end{array}$ & $0 \%$ & $0 \%$ & $0 \%$ & $3 \%$ & $12 \%$ & $12 \%$ & $12 \%$ & $5 \%$ & $0 \%$ \\
\hline $\begin{array}{l}\text { \% Wind / } \\
\text { VRE }\end{array}$ & $0 \%$ & $58 \%$ & $69 \%$ & $68 \%$ & $62 \%$ & $62 \%$ & $62 \%$ & $68 \%$ & $100 \%$ \\
\hline $\begin{array}{l}\% \text { PV / } \\
\text { VRE }\end{array}$ & $0 \%$ & $42 \%$ & $31 \%$ & $29 \%$ & $26 \%$ & $26 \%$ & $26 \%$ & $27 \%$ & $0 \%$ \\
\hline $\begin{array}{l}\text { Min kin. } \\
\text { res. / } 2012\end{array}$ & $27 \%$ & $-45 \%$ & $-49 \%$ & $-63 \%$ & $-74 \%$ & $-83 \%$ & $\mathrm{NC}$ & $-80 \%$ & $-75 \%$ \\
\hline $\begin{array}{l}\text { Mean kin. } \\
\text { res. / } 2012\end{array}$ & $29 \%$ & $-1 \%$ & $-18 \%$ & $-38 \%$ & $-51 \%$ & $-65 \%$ & $\mathrm{NC}$ & $-45 \%$ & $-46 \%$ \\
\hline $\begin{array}{l}\text { Max kin. } \\
\text { res. / } 2012\end{array}$ & $34 \%$ & $20 \%$ & $11 \%$ & $-2 \%$ & $-14 \%$ & $-29 \%$ & $\mathrm{NC}$ & $-16 \%$ & $-20 \%$ \\
\hline
\end{tabular}

NC: Not calculated

\section{CONCLUSIONS, LIMITATIONS OF THE STUDY AND FUTURE RESEARCH}

Renewable energy is one way to tackle environmental issues, resource scarcity and energy dependency. In this study we used a long-term planning model dedicated to the French power system in order to explore different levels of RES penetration. Compared with the initial model described in [41], we refined RES modeling by adding new technologies (ocean energy, storage technologies, new interconnections, demand-response), production curves for wind and solar, revised costs for wind and PV power plants, and a one-week period with low wind and solar production combined with import restrictions. These improvements allowed us to better represent the impacts of RES penetration on power system sizing. We also used the thermodynamic framework described in detail in [37] to assess kinetic and magnetic reserves and gain insight into the evolution of power system reliability with RES penetration. The main results of this study are:

- The shift in power exchanges with neighboring countries (decrease in exports when RES exceeds $60 \%$ in power production and increase in imports for over $80 \%$ RES);

- The massive installation of new power plants from two to three times the amount installed in a $B A U$ scenario depending on the level of RES penetration and the installation pace of new capacities required;

- The need for an adapted regulation framework to remunerate dispatchable power plants (mainly based on fossil and biomass resources), which need to be installed to complete VRE production, but which will only produce a very low number of hours each year, especially biomass power plants in the $100 \%$ RES scenarios; 
- The role of some flexibility options, on demand and imports, which absorb the variability of high RES-based power systems (as well as biomass power plants);

- In our scenarios, storage technologies play a secondary role compared to other flexibility options;

- Power systems' stability, i.e. their ability to deal with disturbances and return to a normal operating state, is likely to deteriorate due to RES penetration even at moderate levels (40\%). If imports or wind turbines did contribute to kinetic reserves, this situation would be improved but not enough to reach current levels of power systems' stability. Nevertheless, this conclusion can be moderated if high biomass potential is available and a limitation is set on VRE penetration;

- Finally, the additional overall cost of integrating RES is assessed at between $11 \%$ and $30 \%$ (respectively for 40\% RES penetration and 100\% RES penetration in the reference scenarios) compared to a $B A U$ scenario and should be even higher when taking into account the national grid and additional technologies to improve kinetic and magnetic reserves.

These results must be interpreted with caution. For this study, we used a prospective model that sheds light on the complex relationship between policy decisions, technical, economic and regulatory issues concerning power systems, and their long-term evolution. Our results show the potential consequences of different RES penetration levels on French power production, thus allowing policy makers to anticipate them. Nevertheless, many assumptions and simplifications were involved in building our model.

First of all, we have not represented neighboring countries' power systems and their evolution. We considered that imports and exports could be used as needed, which is a very optimistic hypothesis. In reality, power exchanges between countries depend on the marginal price differences on a power market and are significantly affected by each country's power mix. To overcome this drawback, it would be interesting to use a model representing a larger region such as Western Europe.

Secondly, our model includes a considerable amount of data on current and future prices, technical characteristics of power plants, etc. Although input data are taken from a bibliography analysis, they are all subject to uncertainty and results could vary with another set of inputs. Moreover, some approximations have been made when considering the technical and economical parameters. For example the time to build new capacities has not been considered in this study. Including such a time factor in our model would change the levelized cost of the different technologies and thus the investment decisions. To rigorously analyze the robustness of our results with input data, we could conduct a systemic sensitivity analysis and establish the most determinant parameters. One interesting sensitivity analysis would be to use different assumptions on storage costs since we determined relatively low investments in these technologies compared to other studies. This result would require more investigation to be fully understood.

Thirdly, our results cannot be taken as proof of the feasibility or non-feasibility of a high level of RES penetration, since the model does not check the demand-supply balance throughout the year for every condition of demand, weather and power plant availability. This verification is an intricate issue beyond the scope of this study and can only be performed by grid operators. Nevertheless, the methodology framework proposed enables us to size the power system in a way theoretically compatible with its main requirements.

Fourthly, further studies should be conducted to validate the assumptions concerning the maximum pace of installation of power plants as well as their maximum potential. For example, in the $100 \%$ RES scenario, more than $8 \mathrm{GW}$ per year have to be installed for 38 
years, which is a huge amount that has never been reached in France. The feasibility of such a pace might depend on policy incentives to push RES power plants and develop a suitable industrial capacity.

Fifthly, we showed in this study that high levels of RES penetration could jeopardize French power system kinetic and magnetic reserves. Therefore, this kind of penetration could require the installation of additional back-up or storage capacities in order to bring kinetic and magnetic reserves to the power system, and as a result increase costs even more. The analysis of the overall costs, taking into account these additional capacities, could be performed by endogenizing kinetic and magnetic indicators into our model, which has been already done for the case of Reunion Island [40].

Lastly, the domestic grid is not represented in our model. However, we may expect that a radical transformation of the French power system, such as simulated in this study, with power plants located in different areas than currently, should result in higher grid costs [55]. More importantly, power transmission issues, such as line flow limits, which could add constraints to renewable power penetration, have not been considered here. In order to address this issue we are currently deriving an approach based on a second-order Kuramoto model adapted to power systems [56]. This approach enables us to determine whether a given power system is able to maintain synchronism depending on its topology and the distribution of power injections from power plants through the grid [57].

Our study should be taken as a first insight into the complex issue of high RES penetration in the French power system to help policy makers understand the potential consequences of such an evolution.

\section{ACKNOWLEDGMENT}

This research was supported by the Chair Modeling for sustainable development, driven by MINES ParisTech, Ecole des Ponts ParisTech, and AgroParisTech; supported by ADEME, EDF, GRTgaz, Schneider Electric and the Ministry of Ecology, Sustainable Development and Energy.

\section{REFERENCES}

[1] European Parliament and Council of the European Union, Directive 2009/28/EC on the promotion of the use of energy from renewable sources. 2009.

[2] European Commission, "2030 Energy Strategy." ec.europa.eu/energy/en/topics/energystrategy/2030-energy-strategy. [Accessed: 04-Nov-2015].

[3] G. Barbose, "Renewables Portfolio Standards in the United States: A Status Update," Washington, D. C., 06-Nov-2013.

[4] Ministère de l'écologie, du développement durable et de l'énergie, "Energy transition for Green growth. User guide for the act and its attendant actions." www.developpementdurable.gouv.fr/Energy-transition-for-Green-growth. [Accessed: 04-Nov-2015].

[5] European Commission, "A Roadmap for moving to a competitive low carbon economy in 2050." eur-lex.europa.eu/legal-content/en/TXT/?uri=CELEX:52011DC0112. [Accessed: 26-Feb-2016].

[6] F. Ueckerdt, L. Hirth, G. Luderer, and O. Edenhofer, "System LCOE: What are the costs of variable renewables?," Energy, vol. 63, pp. 61-75, Dec. 2013.

[7] J. P. Deane, F. Gracceva, A. Chiodi, M. Gargiulo, and B. P. Ó. Gallachóir, "Assessing power system security. A framework and a multi model approach," Int. J. Electr. Power Energy Syst., vol. 73, pp. 283-297, Dec. 2015. 
[8] D. L. Shawhan, "Estimating the Long-Run Effects of Environmental Policies on the Electricity Grid: Prices, Investment, Demand Response and Resulting Carbon Dioxide Emissions," Feb. 2013.

[9] S. Hagspiel, C. Jägemann, D. Lindenberger, T. Brown, S. Cherevatskiy, and E. Tröster, "Costoptimal power system extension under flow-based market coupling," Energy, vol. 66, pp. 654 666, Jan. 2014.

[10]T. Pesch, H.-J. Allelein, and J.-F. Hake, "Impacts of the transformation of the German energy system on the transmission grid," Eur. Phys. J. Spec. Top., pp. 1-15, Jun. 2014.

[11] N. Zhang, Z. Hu, B. Shen, S. Dang, J. Zhang, and Y. Zhou, "A source-grid-load coordinated power planning model considering the integration of wind power generation," Appl. Energy, vol. 168, pp. 13-24, Apr. 2016.

[12] M. G. Rasmussen, G. B. Andresen, and M. Greiner, "Storage and balancing synergies in a fully or highly renewable pan-European power system," Energy Policy, vol. 51, pp. 642-651, Dec. 2012.

[13] S. Y. Park, B.-Y. Yun, C. Y. Yun, D. H. Lee, and D. G. Choi, "An analysis of the optimum renewable energy portfolio using the bottom-up model: Focusing on the electricity generation sector in South Korea," Renew. Sustain. Energy Rev., vol. 53, pp. 319-329, Jan. 2016.

[14] R. Kannan and H. Turton, "A Long-Term Electricity Dispatch Model with the TIMES Framework," Environ. Model. Assess., vol. 18, no. 3, pp. 325-343, Oct. 2012.

[15] J. Nelson, J. Johnston, A. Mileva, M. Fripp, I. Hoffman, A. Petros-Good, C. Blanco, and D. M. Kammen, "High-resolution modeling of the western North American power system demonstrates low-cost and low-carbon futures," Energy Policy, vol. 43, no. 0, pp. 436-447, 2012.

[16] Geoffrey J. Blanford James H. Merrick and D. Young, "A Clean Energy Standard Analysis with the US-REGEN Model," Energy J., vol. 35, no. Special I, 2014.

[17] S. Ludig, E. Schmid, M. Haller, and N. Bauer, "Assessment of transformation strategies for the German power sector under the uncertainty of demand development and technology availability," Renew. Sustain. Energy Rev., vol. 46, pp. 143-156, Jun. 2015.

[18] E. Schmid and B. Knopf, "Quantifying the long-term economic benefits of European electricity system integration," Energy Policy, vol. 87, pp. 260-269, Dec. 2015.

[19] S. Pfenninger and J. Keirstead, "Renewables, nuclear, or fossil fuels? Scenarios for Great Britain's power system considering costs, emissions and energy security," Appl. Energy, vol. 152, pp. 8393, Aug. 2015.

[20] P. Nahmmacher, E. Schmid, L. Hirth, and B. Knopf, “Carpe Diem: A Novel Approach to Select Representative Days for Long-Term Power System Models with High Shares of Renewable Energy Sources," Social Science Research Network, Rochester, NY, SSRN Scholarly Paper ID 2537072, Dec. 2014.

[21] K. Poncelet, E. Delarue, D. Six, J. Duerinck, and W. D'haeseleer, "Impact of the level of temporal and operational detail in energy-system planning models," Appl. Energy, vol. 162, pp. 631-643, Jan. 2016.

[22] J. P. Deane, A. Chiodi, M. Gargiulo, and B. P. Ó Gallachóir, "Soft-linking of a power systems model to an energy systems model," Energy, vol. 42, no. 1, pp. 303-312, Jun. 2012.

[23] A. Pina, C. A. Silva, and P. Ferrão, "High-resolution modeling framework for planning electricity systems with high penetration of renewables," Appl. Energy, vol. 112, pp. 215 - 223, 2013.

[24] Q. Zhang, B. C. Mclellan, T. Tezuka, and K. N. Ishihara, "An integrated model for long-term power generation planning toward future smart electricity systems," Appl. Energy, vol. 112, pp. 14241437, Dec. 2013.

[25] S. Spiecker and C. Weber, "The future of the European electricity system and the impact of fluctuating renewable energy - A scenario analysis," Energy Policy, vol. 65, pp. 185-197, Feb. 2014.

[26] N. E. Koltsaklis and M. C. Georgiadis, "A multi-period, multi-regional generation expansion planning model incorporating unit commitment constraints," Appl. Energy, vol. 158, pp. 310331, Nov. 2015. 
[27] M. Welsch, P. Deane, M. Howells, B. Ó Gallachóir, F. Rogan, M. Bazilian, and H.-H. Rogner, "Incorporating flexibility requirements into long-term energy system models - A case study on high levels of renewable electricity penetration in Ireland," Appl. Energy, vol. 135, pp. 600-615, Dec. 2014.

[28] R. Komiyama and Y. Fujii, "Long-term scenario analysis of nuclear energy and variable renewables in Japan's power generation mix considering flexible power resources," Energy Policy, vol. 83, pp. 169-184, Aug. 2015.

[29] J. Bertsch, C. Growitsch, S. Lorenczik, and S. Nagl, "Flexibility in Europe's power sector - An additional requirement or an automatic complement?," Energy Econ., vol. 53, pp. 118-131, Jan. 2016.

[30] V. Mazauric and N. Maïzi, "A global approach of electromagnetism dedicated to further longterm planning," PAMM, vol. 7, no. 1, pp. 2130003-2130004, Dec. 2007.

[31] M. Drouineau, N. Maïzi, and V. Mazauric, "Impacts of intermittent sources on the quality of power supply: The key role of reliability indicators," Appl. Energy, vol. 116, pp. 333-343, Mar. 2014.

[32] M. Drouineau, E. Assoumou, V. Mazauric, and N. Maïzi, "Increasing shares of intermittent sources in Reunion Island: Impacts on the future reliability of power supply," Renew. Sustain. Energy Rev., vol. 46, pp. 120-128, Jun. 2015.

[33] S. Bouckaert, V. Mazauric, and N. Maïzi, "Expanding Renewable Energy by Implementing Demand Response," Energy Procedia, vol. 61, pp. 1844-1847, 2014.

[34] S. Bouckaert, P. Wang, V. Mazauric, and N. Maïzi, "Expanding Renewable Energy by Implementing Dynamic Support through Storage Technologies," Energy Procedia, vol. 61, pp. 2000-2003, 2014.

[35] R. Loulou, G. Goldstein, U. Remme, A. Kanudia, A. Lehtila, "Documentation for the TIMES Model," ETSAP, Apr. 2005.

[36] ADEME (Agence de l'Environnement et de la Maîtrise de l'Energie), Artelys, ARMINES-PERSEE, and Energies Demain, "A 100\% renewable power mix? Analyses and optimizations (Mix électrique 100\% renouvelable ? Analyses et optimisations)," Angers, France, 8596, Oct. 2015.

[37] M. Drouineau, "Long-term planning using a multi-scale approach: the issue of power system dynamics (Modélisation prospective et analyse socio-temporelle : intégration de la dynamique du réseau électrique)," Mines ParisTech, Sophia-Antipolis, France, 2011.

[38] N. Maïzi and E. Assoumou, "Future prospects for nuclear power in France," Applied Energy, pp. 849-859, Dec-2014.

[39] Réseau de Transport d'Electricité, "Production d'électricité par filière." www.rtefrance.com/fr/eco2mix/eco2mix. [Accessed: 26-Feb-2016].

[40] S. Bouckaert, "Assessing Smart Grids contribution to the energy transition with long-term scenarios (Contribution des Smart Grids à la transition énergétique: évaluation dans des scénarios long terme)," Mines ParisTech, Sophia-Antipolis, France, 2013.

[41] E. Assoumou, "MARKAL modelling for long term energy planning in the French energy context (Modélisation MARKAL pour la planification énergétique long terme dans le contexte français)," Ecole des Mines de Paris, Sophia-Antipolis, France, 2006.

[42] International Energy Agency, "Technology Roadmap Solar Photovoltaïc Energy - 2014 Edition," OECD/IEA, Paris, France, 2014.

[43] International Energy Agency, "Technology Roadmap: Wind Energy - 2013 edition," OECD/IEA, Paris, France, 2013.

[44] Commission de Régulation de l'Energie, "Renewable energies costs and profitability in France (Coûts et la rentabilité des énergies renouvelables en France métropolitaine)," CRE, Paris, France, Apr. 2014.

[45] Réseau de Transport d'Electricité, "The longest underground interconnection for this power level (La liaison souterraine la plus longue du monde à ce niveau de puissance)," RTE \& Vous - le MAG. 
lemag.rte-et-vous.com/dossiers/la-liaison-souterraine-la-plus-longue-du-monde-ce-niveau-depuissance. [Accessed: 26-Feb-2016].

[46] Enea Consulting, "Energy storage - Issues, technical solutions and enhancement opportunities (Le stockage d'énergie - Enjeux, solutions technique et opportunités de valorisation)," Paris, France, Mar. 2012.

[47] International Energy Agency, "World Energy Outlook 2013," OECD/IEA, Paris, France, Nov. 2013.

[48] Réseau de Transport d'Electricité, "Forecast assessment of electricity supply-demande balance in France (Bilan prévisionnel de l'équilibre offre-demande d'électricité en France - édition 2014)," Direction de l'économie, de la prospective et de la transparence, RTE, La Défense, France, Sep. 2014.

[49] French Agency on Environment and Energy Management (ADEME), "ADEME forecasting study for 2030 and 2050 (L'exercice de prospective de l'ADEME 'Vision 2030-2050')," Angers, France, Jun. 2013.

[50] R. Bourbonnais and J. H. Keppler, "Assessment of price elasticity of power demand in France (Estimation de l'élasticité prix de la demande électrique en France)," Université Paris Dauphine, Paris, France, 2013.

[51] F. Benhmad and J. Percebois, "Wind power feed-in impacts on electricity system," CREDEN, Université Montpellier 1, Montpellier, France, Nov. 2014.

[52] D. Chattopadhyay and T. Alpcan, "A Game-Theoretic Analysis of Wind Generation Variability on Electricity Markets," IEEE Trans. Power Syst., vol. 29, no. 5, pp. 2069-2077, Sep. 2014.

[53] C. Budischak, D. Sewell, H. Thomson, L. Mach, D. E. Veron, and W. Kempton, “Cost-minimized combinations of wind power, solar power and electrochemical storage, powering the grid up to 99.9\% of the time," J. Power Sources, vol. 225, pp. 60-74, Mar. 2013.

[54] A. G. González Rodriguez, A. González Rodriguez, and M. Burgos Payán, "Estimating wind turbines mechanical constants," presented at the International Conference on Renewable Energies and Power Quality - ICREPQ, Sevilla, 2007.

[55] European Network of Transmission System Operators for Electricity (entsoe), "10-Year Network Development Plan 2014," Brussels, Belgium.

[56] F. Dörfler, "Dynamics and Control in Power Grids and Complex Oscillator Networks," University of California, Santa Barbara, 2013.

[57] V. Krakowski, N. Maïzi, and V. Mazauric, "Sustainable design of power systems: A fully magnetic multi-scale model dedicated to grid stability," presented at the MMM-Intermag Conference, San Diego, 2016. 